\title{
Hypogean Quedius of Taiwan and their biogeographic significance (Coleoptera: Staphylinidae: Staphylininae)
}

\author{
Fang-Shuo HU ${ }^{1}$, Amalia BOGRI ${ }^{2}$, Alexey SOLODOVNIKOV ${ }^{3} \&$ Aslak Kappel HANSEN ${ }^{4, *}$ \\ ${ }^{1}$ Department of Entomology, National Chung Hsing University, \\ 145 Xingda Rd., South Dist., Taichung, 40227, Taiwan. \\ 2,3,4 Natural History Museum of Denmark, University of Copenhagen, \\ Universitetsparken 15, Copenhagen 2100, Denmark. \\ ${ }^{4}$ Natural History Museum Aarhus, Wilhelm Meyers Allé 10, 8000 Aarhus, Denmark. \\ ${ }^{4}$ Department of Bioscience, University of Aarhus, Ny Munkegade 116, 8000 Aarhus, Denmark. \\ *Corresponding author: akhansen@snm.ku.dk \\ ${ }^{1}$ Email: fangshuo hu@smail.nchu.edu.tw \\ 2Email: amalia.bogri.93@gmail.com \\ ${ }^{3}$ Email: asolodovnikov@snm.ku.dk

\footnotetext{
${ }^{1}$ urn:Isid:zoobank.org:author:49A66DB4-625F-4CD6-9512-1AE6396F4851

${ }^{2}$ urn:lsid:zoobank.org:author:318FE942-705C-4540-92E1-0D51F63686B8

${ }^{3}$ urn:lsid:zoobank.org:author:E56B0FF6-38F5-48D7-A5C1-0EA071EB4A99

${ }^{4}$ urn:1sid:zoobank.org:author:D1FBF5E1-6876-48EF-978C-FFDADFF7334C
}

\begin{abstract}
As a result of the integrative (morphology and DNA barcodes) revision of the Taiwanese species of the rove beetle genus Quedius belonging to the abnormalis group, in the subgenus Microsaurus, three valid hypogean species are reported for the fauna of this island: Quedius masuzoi Watanabe, 1989, Q. nishikawai Watanabe, 1991 and Q. adilus sp. nov. A new synonymy, Quedius masuzoi = Quedius chiangi Smetana, 1995 syn. nov., is established along with providing additional records, a larval description and bionomic information for this species. Finally, the biogeographic origin of the abnormalis group in Taiwan is discussed.
\end{abstract}

Keywords. Subterranean, new species, larva, Quediini, Microsaurus.

Hu F.-S., Bogri A., Solodovnikov A. \& Hansen A.K. 2020. Hypogean Quedius of Taiwan and their biogeographic significance (Coleoptera: Staphylinidae: Staphylininae). European Journal of Taxonomy 664: 1-24.

https://doi.org/10.5852/ejt.2020.664

\section{Introduction}

Quedius Stephens, 1829 is one of the largest rove beetle genera, with more than 700 species globally. Thirty-eight species of this genus occur in Taiwan, of which 35 are endemic to the island. The Taiwanese fauna of Quedius has been extensively studied by Smetana (1995, 1996, 2001a, 2019). The isolated geographic location, large elevation variation, warm climate and heavy rainfall of Taiwan enables a 
large variation of habitats which, together with the rate of new species being reported in these papers, suggests that there are still many undescribed species of Quedius to be found there.

Quedius is a polyphyletic genus (Brunke et al. 2016), that includes lineages which differ in their biology. Although the majority of species live in leaf litter, there are a number of hypogean species, mainly found in the subgenus Microsaurus (Fig. 1). The hypogean species of Quedius have evolved specialized morphological traits such as brachyptery, microphthalmy, dorso-ventrally flattened body and longer appendages, to mention the most obvious adaptations (Vandel 1964; Culver 1982).

In Taiwan, only three such hypogean species have been known, namely $Q$. chiangi Smetana, 1995, Q. masuzoi Watanabe, 1989 and Q. nishikawai Watanabe, 1991. All of them belong to the abnormalis group as defined by Uéno \& Watanabe (1966) and all are endemic to this island (Watanabe 1989, 1991; Smetana 1995). Because the derived hypogean morphology masks their phylogenetic affinities, the hypogean species of Quedius are only loosely arranged in tentative species groups (Solodovnikov \& Hansen 2016), with the composition of the abnormalis group remaining somewhat unclear. According to current views, the main diversity of this species group is concentrated in Japan (29 species out of 32; Uéno \& Watanabe 1966, 1970; Watanabe \& Yoshida 1970, 2008; Watanabe 1981, 1986, 1987, $1990,2000,2008,2009)$. Smetana (1995) hypothesized that the entire abnormalis group is sister to the monotypic yun group from Taiwan. Later, he suggested that the abnormalis group could be related to the przewalskii group from Central Southern China (Smetana 2001b).

As is true for all hypogean Quedius, the three Taiwanese species of the abnormalis group are known from very limited material, mostly of female specimens. Only $Q$. masuzoi has been described based on

\section{Genus Quedius}

Distribution: mainly Holarctic

Number of species: worldwide $>700$

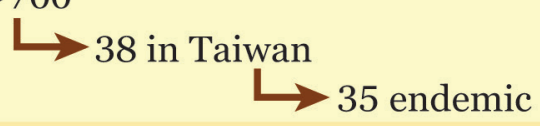

\section{Subgenus Microsaurus}

Distribution: mainly Holarctic

Number of species: worldwide $>330$

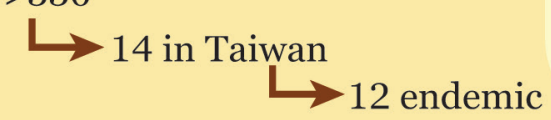

many species tend to live in crevices \& cavities, often nidicolous or hypogean

\section{abnormalis-group not well-defined group}

Distribution: Taiwan, Japan

Number of species: total 32

$\longrightarrow 3$ in Taiwan, endemic

all species hypogean

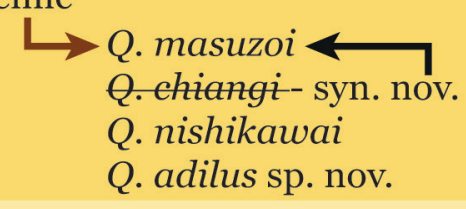

Fig. 1. Infographic summary of species diversity, endemism and ecology of relevant species of Quedius Stephens, 1829. 
a male specimen, even though a singleton, for which Watanabe (1989) and Smetana (1995) provided several illustrations of the aedeagus. The identity of $Q$. chiangi and $Q$. nishikawai remains ambiguous, as only two females are available for the former and one female for the latter species.

This study was triggered by the relatively extensive new material, including larvae, which was recently collected in Taiwan and which necessitated a taxonomic revision of all three hitherto known hypogean Taiwanese species of Quedius, including a more rigorous assessment of characters previously used for their delimitation. As a result, we describe one new species, propose one new synonym and describe the larva of $Q$. masuzoi, which is the first known larva for the abnormalis group. The presumably stenotopic and poorly dispersing hypogean species are particularly interesting as model organisms for biogeographic studies. Therefore, we conclude the paper with a discussion of how the species of the abnormalis group could be used to explore the biogeographic connections of the fauna of Taiwan.

\section{Material and methods}

\section{Specimen examination, illustrations and measurements}

Adult specimens were examined, either in alcohol or card-mounted, using a Leica M205 C stereoscope. Female genital segments from dissected specimens were examined in glycerin. Aedeagi and male genital segments were examined in glycerin from both alcohol-preserved specimens and after dissection and clearing with potassium hydroxide of the card-mounted specimens. Dissected terminalia were then stored in glycerin inside a microvial pinned with the respective specimen. Drawings of the morphological structures were made either freehand using a camera lucida or from photographs (aedeagus) and digitally inked in Adobe Illustrator CS ver. 5.1 (Adobe, San Jose, CA, USA). Stack images were made with a Canon EOS 5D Mark III digital camera fitted with a Canon MP-E65 f2.8 1-5 × macro lens or a Canon EOS 6D DSLR digital camera mounted on a Leica M205 C stereoscope. Images were imported to Zerene Stacker ver. 1.04 (Zerene Systems, Richland, WA, USA) and stacked using the Pmax function. Photos of the habitat and of live specimens were taken with either an Olympus OM-D E-M1 with an Olympus M. Zuiko Digital ED $30 \mathrm{~mm}$ F3.5 lens or a Canon Power Shot G16. Image cleaning and background removal were done in Adobe Photoshop CS ver. 5.1. Measurements were taken with an ocular eyepiece micrometre; they are given in $\mathrm{mm}$ and are abbreviated as follows:
$\mathrm{A} 4 \mathrm{~L}=$ length of antennal segment 4
$\mathrm{A} 4 \mathrm{~W}=$ width of antennal segment 4
$\mathrm{EL}=$ maximum length of eye
$\mathrm{HL}=$ length of head from base of labrum to nuchal ridge
$\mathrm{HW}=$ maximum width of head
$\mathrm{PL} \quad=$ maximum length of pronotum
$\mathrm{PW}=$ maximum width of pronotum
$\mathrm{TL}=$ maximum length of tempora

The larval description of Quedius masuzoi is based on four (third instar $-\mathrm{L}_{3}$ ) larvae that were collected at the same locality as the adults (for details, see 'Material examined' below) and matched with them via DNA analysis (for details, see 'DNA work' and 'Molecular results and identity of the new material' below). Larvae were studied with the dissecting Leica M125 scope while they were immersed in $96 \%$ ethanol and some, in more detail, in propylene glycol, where they were macerated for a day to slightly soften. Our description is made primarily for diagnostic purposes; therefore, we did not apply compound microscopy or more specific preparations, techniques used in more specialised larval studies (e.g., Pietrykowska-Tudruj et al. 2011, 2014). For the same reason, and because of the fragmented knowledge of the larvae of Quedius and other Staphylinidae, we do not here attempt to homologise 
all chaetotaxic elements of the larvae of $Q$. masuzoi with those of other known larvae of Staphylininae and allies. In fact, even within this group of rove beetles, there is a variety of approaches on how to describe chaetotaxy; see, for example, Solodovnikov \& Newton (2005) and Pietrykowska-Tudruj et al. (2011, 2014). Here, for practical purposes, we made our description as compatible as possible with other detailed larval descriptions of Quedius in Pietrykowska-Tudruj et al. (2014), including establishing chaetotaxic homologies. All line illustrations were made using a camera lucida attached to the microscope and then digitally 'inked' in Adobe Illustrator. Stack images of the habitus of the larva were made with a Canon EOS 760D SLR digital camera fitted with a Canon MP-E65 f2.8 1-5× macro lens. Images were imported to CombineZP (Hadley 2010) with the settings 'Align and Balance Used Frames' for alignment and 'Do Stack' for merging. All measurements were made with an ocular micrometre and are given in mm. General measurements of larvae comprised: total body length - from apical margin of nasale to the apex of abdominal segment IX (abdominal segment X (pygopod) is bent ventrad and thus its apex is not a good landmark); head length - from apex of paramedial tooth of nasale to neck constriction; head and pronotum width - maximal width; pronotum length - from apical carina to basal carina along medial line of pronotum.

\section{Depositories}

$\mathrm{CNC}=$ Canadian National Collection of Insects and Arthropods, Ottawa, Canada (A. Brunke)

FSHc = Fang-Shuo Hu's private collection, Taichung, Taiwan

NHMD = Natural History Museum of Denmark, Copenhagen, Denmark (includes former ZMUC) (A. Solodovnikov)

NMNS $=$ National Museum of Natural Science, Taichung, Taiwan (J.-F. Tsai and M.-L. Chan)

NSMT $=$ National Museum of Nature and Science, Tsukuba, Japan (S. Nomura)

\section{DNA work}

The complete genomic DNA was extracted from six specimens of putative Quedius masuzoi, including both adults $(n=4)$ and larvae $(n=2)$, using the Tissue Genomic DNA Mini Kit (Geneaid Biotech Ltd, New Taipei, Taiwan) following the manufacturer's protocol, but with adapted incubation periods (14 hours in proteinase $\mathrm{K}+\mathrm{GT}$ buffer, 1 hour in proteinase $\mathrm{K}+\mathrm{GT}$ buffer + LGT buffer). We amplified the 5' fragment of the cytochrome oxidase I(CO1) mitochondrial gene using the standard LCO1490/HCO2198 primers (Folmer et al. 1994) with the following PCR protocol: $94^{\circ} \mathrm{C}$ for $3 \mathrm{~min}, 35 \times\left(94^{\circ} \mathrm{C}\right.$ for $0: 30 \mathrm{~min}$, $48^{\circ} \mathrm{C}$ for $0: 45 \mathrm{~min}, 72^{\circ} \mathrm{C}$ for $\left.1: 00 \mathrm{~min}\right), 72^{\circ} \mathrm{C}$ for $8 \mathrm{~min}$. We aligned the forward and reverse sequences and fitted our primers. After alignment, the consensus sequences were checked for potential sequencing errors (ambiguous calls) and were manually edited. Our sequences were aligned with sequences of Quedius scitus (Gravenhorst, 1806) and Q. mesomelinus (Marsham, 1802) from GenBank using the MUSCLE algorithm in Geneious ver. 6.1. The aligned dataset was imported to MEGA ver. 7.0 software (Kumar et al. 2018), where we calculated the mean genetic distances between and within each species and built a maximum likelihood species tree using the GTR function. Newly generated CO1 sequences of Q. masuzoi were submitted to GenBank. GenBank numbers for Q. scitus, Q. mesomelinus and Q. masuzoi are provided in Table 1 .

\section{Georeferencing and mapping}

Collecting localities for all known material of the abnormalis group in Taiwan are mapped here for the first time (Fig. 2) using SimpleMappr. Except for some of our newly added material, none of the specimens from previous studies were georeferenced at the time of collecting. Therefore, their geographic coordinates, as provided in Table 2 and on Fig. 2, are approximate and have been obtained from searches of label localities and their subsequent georeferencing using Google Earth. 
Table 1. List of analyzed specimens with DNA barcodes and their GenBank accession numbers.

\begin{tabular}{ccc}
\hline Species & Voucher number & GenBank number \\
\hline Quedius (Microsaurus) masuzoi Watanabe, 1998 & FS001 & MN989304 \\
Quedius (Microsaurus) masuzoi Watanabe, 1998 & FS002 & MN989305 \\
Quedius (Microsaurus) masuzoi Watanabe, 1998 & FS003 & MN989306 \\
Quedius (Microsaurus) masuzoi Watanabe, 1998 & FS004 & MN989307 \\
Quedius (Microsaurus) masuzoi Watanabe, 1998 & FS008L & MN989308 \\
Quedius (Microsaurus) masuzoi Watanabe, 1998 & FS010L & MN989309 \\
Quedius (Microsaurus) mesomelinus (Marsham, 1802) & ZFMK-TIS-2506907 & KU910458 \\
Quedius (Microsaurus) mesomelinus (Marsham, 1802) & ZFMK-TIS-2512280 & KU915458 \\
Quedius (Microsaurus) mesomelinus (Marsham, 1802) & ZMUO<FIN>:005802 & KJ965891 \\
Quedius (Microsaurus) mesomelinus (Marsham, 1802) & ZFMK-TIS-2512533 & KU912513 \\
Quedius (Microsaurus) mesomelinus (Marsham, 1802) & GBOL_Col_FK_1552 & KM442393 \\
Quedius (Microsaurus) scitus (Gravenhorst, 1806) & ZFMK-TIS-2505538 & KU907791 \\
Quedius (Microsaurus) scitus (Gravenhorst, 1806) & ZFMK-TIS-2537164 & KU908811 \\
Quedius (Microsaurus) scitus (Gravenhorst, 1806) & ZFMK-TIS-2510036 & KU916325 \\
Quedius (Microsaurus) scitus (Gravenhorst, 1806) & ZMUO<FIN>:003950 & KJ965037 \\
\hline
\end{tabular}

\section{Results}

Class Insecta Linnaeus, 1758

Order Coleoptera Linnaeus, 1758

Family Staphylinidae Latreille, 1802

Subfamily Staphylininae Latreille, 1802

Tribe Quediini Kraatz, 1857

Genus Quedius Stephens, 1829

Subgenus Microsaurus Dejean, 1833

Quedius masuzoi Watanabe, 1989

Figs 2, 3A-B, D-E, G-H, 4A, 9B (adult); 5-8, 9C (larva)

Quedius masuzoi Watanabe, 1989: 170, figs 1-4 (description; type locality: Taiwan, Nan-t'ou Hsien, Mt Neng-kao-pei-feng [= 能高北峰 $=$ 南華山 = Nanhua Mt], alt. $2870 \mathrm{~m}$ ).

Quedius chiangi Smetana, 1995: 48, fig. 54 (description). Syn. nov.

Quedius masuzoi - Smetana 1995: 45, figs 49-53 (redescription).

\section{Diagnosis (adult)}

Quedius masuzoi (Fig. 4A) is very similar to the two other species of the abnormalis group in Taiwan. From Q. nishikawai it can be distinguished by the shorter antenna and sclerotization pattern of tergite X, which has a distinctly heavier sclerotized stalk connecting its more sclerotized apical and basal areas (compare Figs 3G, H and 4I). From Q. adilus sp. nov. it can be distinguished by the shorter and wider median lobe of the aedeagus, which is only slightly protruding over the apical margin of the bilobed paramere (in parameral view) (compare Fig. 3A-B and 3C). 


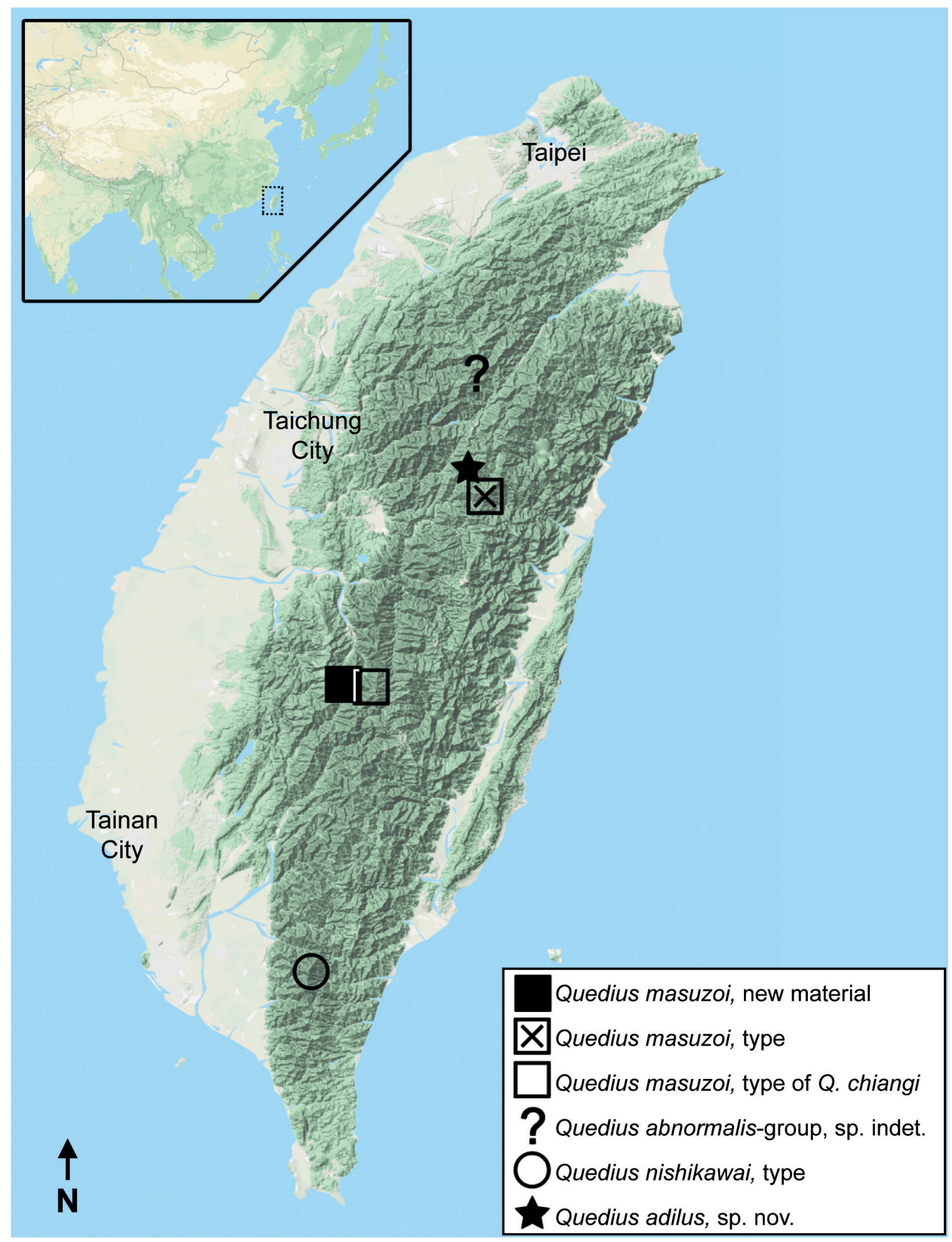

Fig. 2. Distribution of species in the Quedius abnormalis group in Taiwan. Filled square $\mathbf{\square}$ refers to the new specimens of adults and larvae of Quedius masuzoi Watanabe, 1989 reported in this paper. Square with cross $\otimes$ is the type locality of Quedius masuzoi. Unfilled square $\square$ is the type locality of Quedius chiangi Smetana, 1995, junior synonym of Q. masuzoi. Question mark (?) refers to an undescribed female specimen reported in Watanabe (1989). Unfilled circle $O$ is the type locality of Quedius nishikawai Watanabe, 1991. Filled star $\star$ is the type locality of Quedius adilus sp. nov. 
HU F.-S. et al., Hypogean Quedius of Taiwan

Table 2. Label information on the currently known specimens of the Quedius abnormalis group from Taiwan.

\begin{tabular}{|c|c|c|c|c|c|}
\hline Species & Locality & Elevation & Lat $\left({ }^{\circ} \mathbf{N}\right)$ & Long $\left({ }^{\circ} \mathbf{E}\right)$ & Notes \\
\hline $\begin{array}{l}\text { Q. nishikawai } \\
\text { Watanabe, } 1991\end{array}$ & Mt Pei-ta-wu Shan & $2520 \mathrm{~m}$ & 22.62 & 120.76 & + , Cat. no. $427 \mathrm{ST} 0012 \mathrm{H}$ \\
\hline $\begin{array}{c}\text { Q. chiangi } \\
\text { Smetana, } 1995\end{array}$ & $\begin{array}{c}\text { Nantou Hsien, } \\
\text { Yushan N.P., Pai-Yun Hut }\end{array}$ & $3528 \mathrm{~m}$ & 23.4664 & 120.9498 & q, NMNS \\
\hline $\begin{array}{c}\text { Q. chiangi } \\
\text { Smetana, } 1995\end{array}$ & $\begin{array}{l}\text { Nantou Hsien, } \\
\text { Mt Yushan }\end{array}$ & - & 23.46 & 120.94 & + , Y. Hayashi collection \\
\hline $\begin{array}{c}\text { Q. masuzoi } \\
\text { Watanabe, } 1989\end{array}$ & Mt Neng-kao-pei-feng & $2870 \mathrm{~m}$ & 24.03 & 121.28 & ô, Cat. no. $427 \mathrm{ST} 0013 \mathrm{H}$ \\
\hline $\begin{array}{c}\text { Q. masuzoi } \\
\text { Watanabe, } 1989\end{array}$ & Shi Mt race, Alishan To. & $2360 \mathrm{~m}$ & 23.4691 & 120.8583 & 4 ồ, 5 우, 4 larvae \\
\hline Q. adilus sp. nov. & Yuanfeng, Nantou Co. & ca $2750 \mathrm{~m}$ & 24.11 & 121.23 & $\sigma^{\lambda}$ \\
\hline $\begin{array}{l}\text { Q. abnormalis } \\
\text { group member }\end{array}$ & $\begin{array}{l}\text { San-liu-chiu on } \\
\text { Mt Hsüeh Shan }\end{array}$ & $3500 \mathrm{~m}$ & 24.3922 & 121.2545 & 우 \\
\hline
\end{tabular}

Diagnosis (larva)

Head capsule parallel-sided, not narrowing anteriad towards bases of mandibles, with four weakly visible white stemmata on each side, without dark pigment spots inside them; frayed setae present from metathorax to apex of abdomen; apotome with short stalk not extending beyond tentorial pits (Fig. 6B); inner margin of mandible without small tooth (Fig. 6A, E); maxillary and labial palp 3- and 2-segmented, respectively, last segment of maxillary palp longer than penultimate segment, weakly divided into two pseudosegments (Fig. 6E); protibial comb with irregular row of 8-10 split (bifid) spines (Fig. 7C).

Material examined (all adults unless indicated as larvae)

Holotype (of Quedius chiangi)

TAIWAN ・ ' ; Nantou Hsien, Yushan Natonal Park, Pai-Yun Hut [玉山 排雲山莊]; alt. 3528 m; 15 May 1991; "A. Smetana [T83] / HOLOTYPE"; "Quedius chiangi A. Smetana 1993 [red label, hand writing]"; NMNS.

\section{Other material}

TAIWAN ・ 1 ð, 1 平; Chiayi Co., Shi Mt race [石山引水道], Alishan To; $23.4691^{\circ} \mathrm{N}, 120.8583^{\circ} \mathrm{E}$; alt. 2360 m; 11 Feb. 2019; Y.T. Lai leg.; subterranean water diversion construction; NHMD • 1 §ं; same collection data as for preceding; 23 Feb. 2019; F.S. Hu leg.; FSHc • 1 đ; same collection data as for preceding; DNA voucher specimen FS001 (GenBank: MN989304); NMNS • 1 \%; same collection data as for preceding; 11 Feb. 2019; Y.T. Lai leg.; DNA voucher specimen FS002 (GenBank: MN989305); FSHc • 1 \%; same collection data as for preceding; 3 Feb. 2019; Y.T. Lai leg.; DNA voucher specimen FS003 (GenBank: MN989306); FSHc • 1 q; same collection data as for preceding; 23 Feb. 2019; B.H. Ho leg.; DNA voucher specimen FS004 (GenBank: MN989307); NMNS • 1 ô; same collection data as for preceding; F.S. Hu leg.; DNA voucher specimen FS005; NMNS • 1 o; ; same collection data as for preceding; 24 Feb. 2019; F.S. Hu leg.; DNA voucher specimen FS006; NMNS • 1 q; same collection data as for preceding; DNA voucher specimen FS007; NMNS $\bullet 1$; ; same collection data as for preceding; 21 Feb. 2020; W.Z. Tseng and H.Y. Lin leg; FSHc • 2 larvae; same collection data as for preceding; 23 Feb. 2019; F.S. Hu leg.; DNA voucher specimens FS008L (GenBank: MN989308), FS009L [2 specimens in different vials]; FSHc - 2 larvae; same collection data as for preceding; DNA voucher specimens FS010L (GenBank: MN989309), FS011L [2 specimens in different vials]; NHMD. 


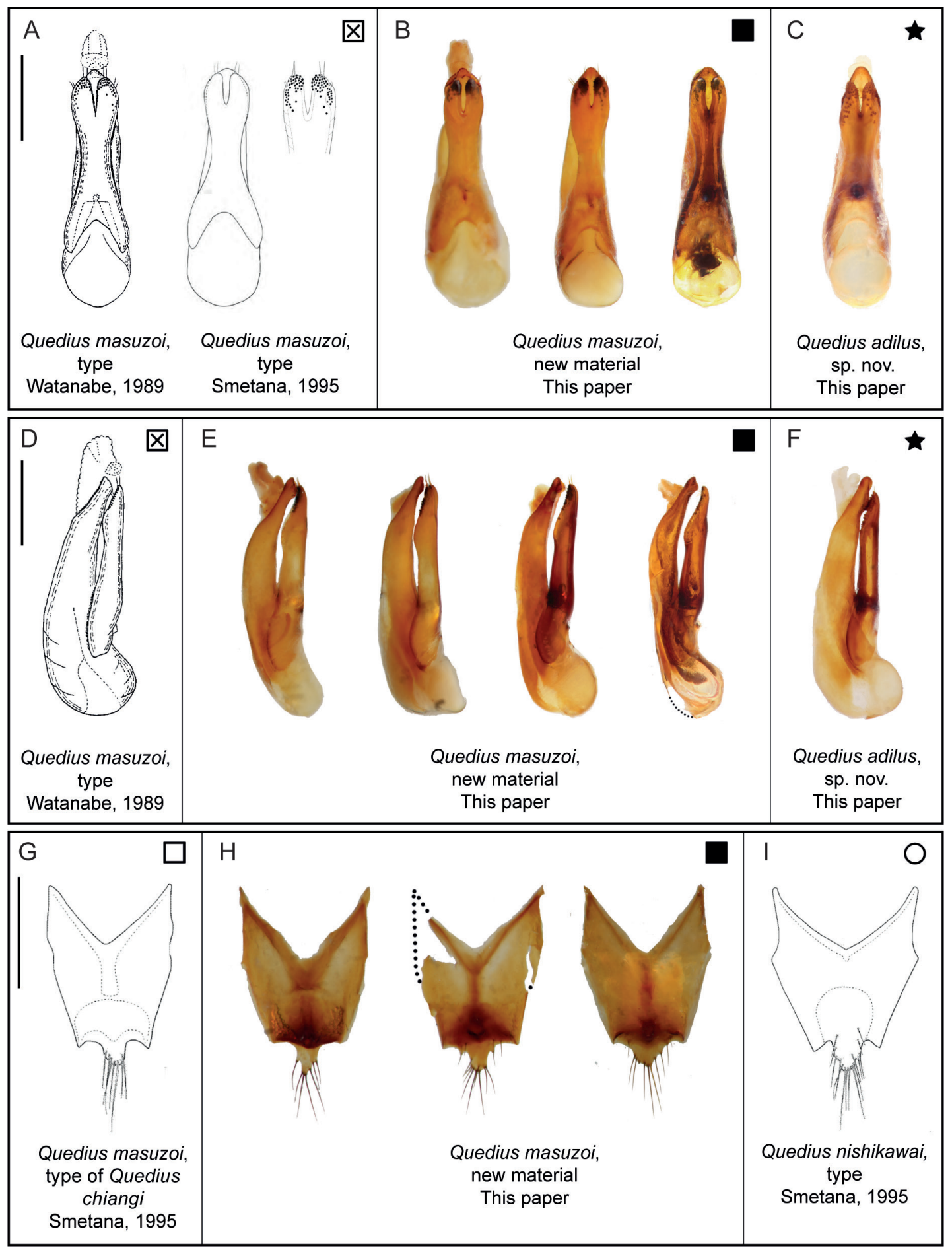

Fig. 3. Aedeagi and female terminalia of species of the Quedius abnormalis group from Taiwan. The graphic symbol on each illustration refers to the collection locality on Fig. 2 as follows: filled square to the new specimens of Quedius masuzoi Watanabe, 1989 reported in this paper; square with cross $\square$ to the male holotype of Quedius masuzoi; unfilled square $\square$ to the female holotype of Quedius chiangi Smetana, 1995, synonym of $Q$. masuzoi; unfilled circle $O$ to the female holotype of Quedius nishikawai Watanabe, 1991; filled star $\star$ to the male holotype of Quedius adilus sp. nov. Top row (A-C): parameral view of aedeagus. Middle row (D-F): lateral view of aedeagus. Bottom row $(\mathbf{G}-\mathbf{I})$ : female tergite X. Scale bars $=0.5 \mathrm{~mm}$. 
Description (adult)

Male

See Watanabe (1989) and Smetana (1995).

\section{Female}

See original description of Q. chiangi in Smetana (1995).

\section{Character variability and new synonymy}

Smetana (1995) described Q. chiangi as a species very similar to Q. masuzoi, but differing from the latter in the position of the posterior frontal puncture and the number of its additional setiferous punctures. Smetana (1995) expressed the position of the frontal puncture as a ratio of the distances between that and the hind margin of the head to the distance between the frontal puncture and the hind margin of the eye. According to this, the posterior frontal puncture is positioned at a ratio of no more than 1.5 in

A

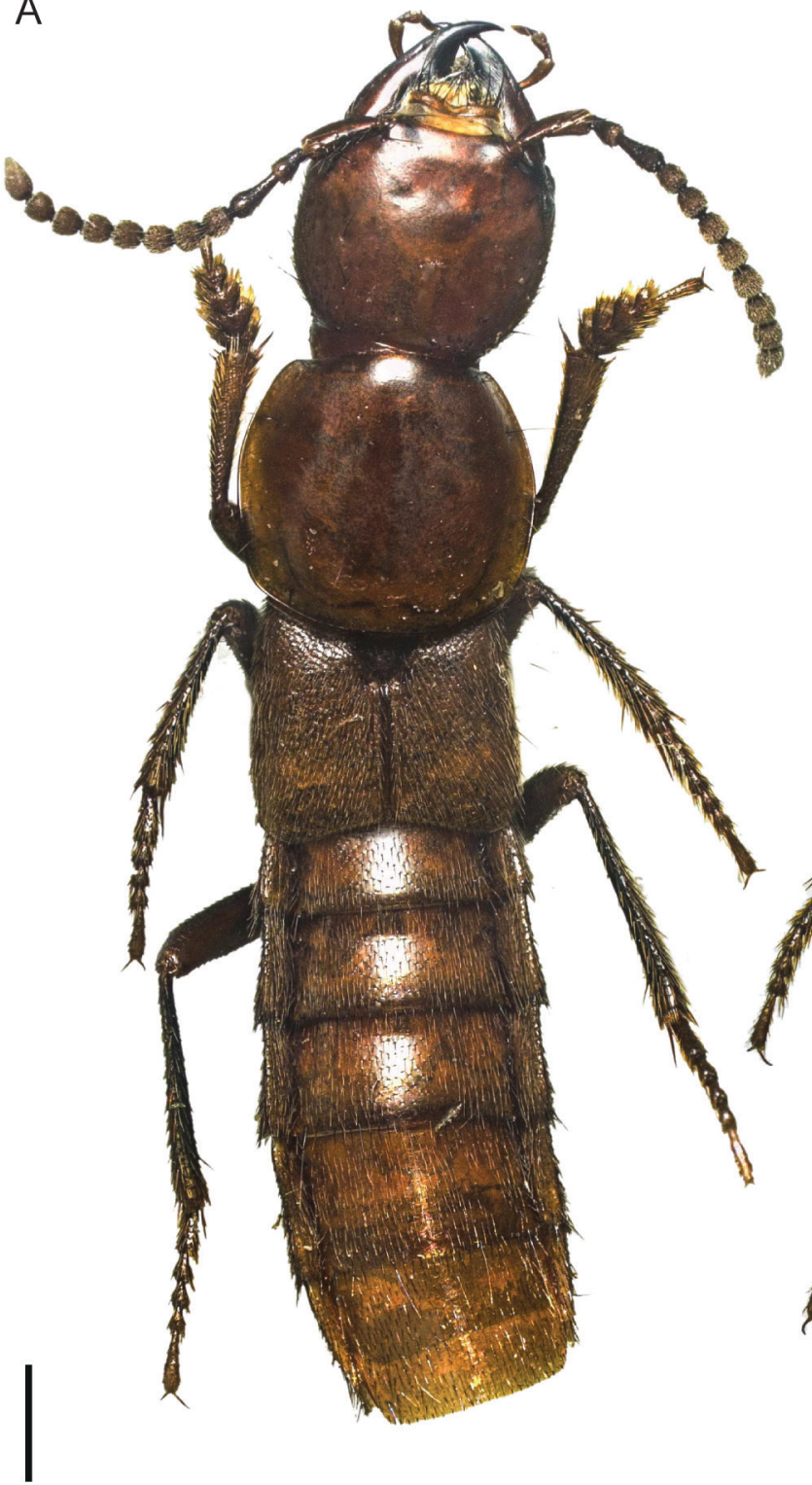

B

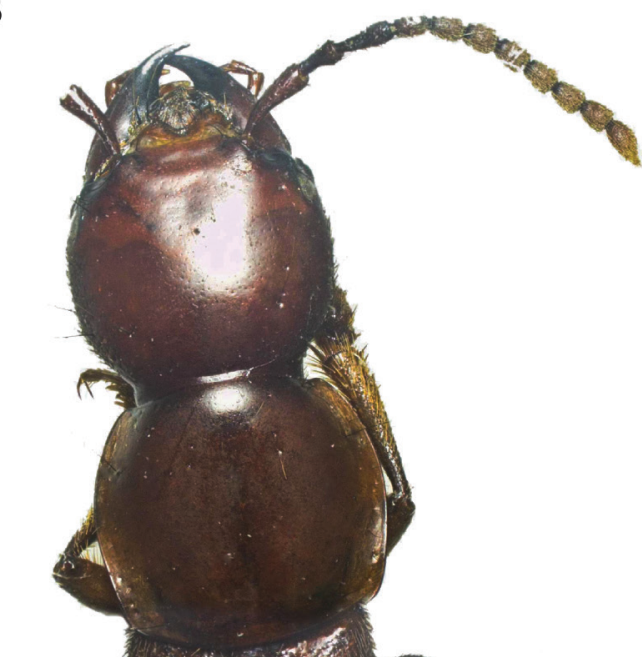

Fig. 4. Habitus images of holotypes. A. Quedius masuzoi Watanabe, 1989. B. Quedius nishikawai Watanabe, 1991. Scale bar $=1 \mathrm{~mm}$. 
Q. masuzoi, whereas in $Q$. chiangi this ratio is roughly 3.5, which in effect means that this puncture in $Q$. chiangi is positioned much closer to the hind margin of the eye. Furthermore, Smetana (1995) mentioned one additional setiferous puncture posteriad of the posterior frontal puncture in $Q$. masuzoi and two to three punctures postero-mediad of the posterior frontal puncture in $Q$. chiangi.

Our new material with the sequenced CO1 barcode, however, shows that the mentioned traits are quite variable even within our sample of specimens from the same locality with identical barcodes. We found that the position of the posterior frontal puncture, expressed in the same ratio as Smetana (1995), varies in our sample between 1.46 and 4.90, meaning that the intraspecific variability range encompasses the differences reported as interspecific by Smetana (1995). One of our specimens was completely missing the posterior frontal puncture on one side. Remarkably, the position and number of additional setiferous punctures near the posterior pronotal puncture also vary in our specimens, ranging from missing through having one anterio-mediad to having multiple posterio-mediad.

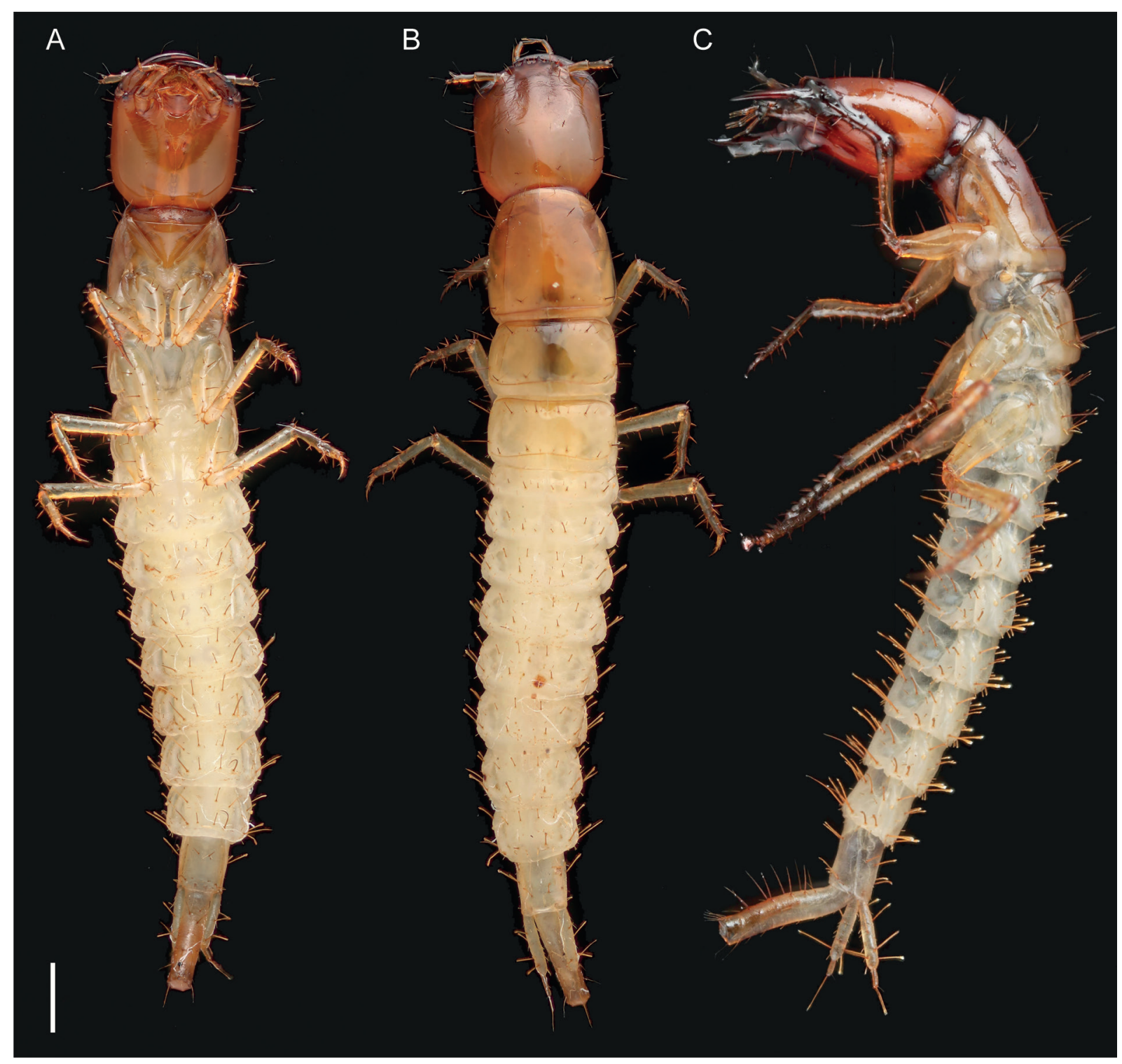

Fig. 5. Quedius masuzoi Watanabe, 1989. Photographs of larvae. A. Ventral view. B. Dorsal view. C. Lateral view. Scale bar $=1 \mathrm{~mm}$. 

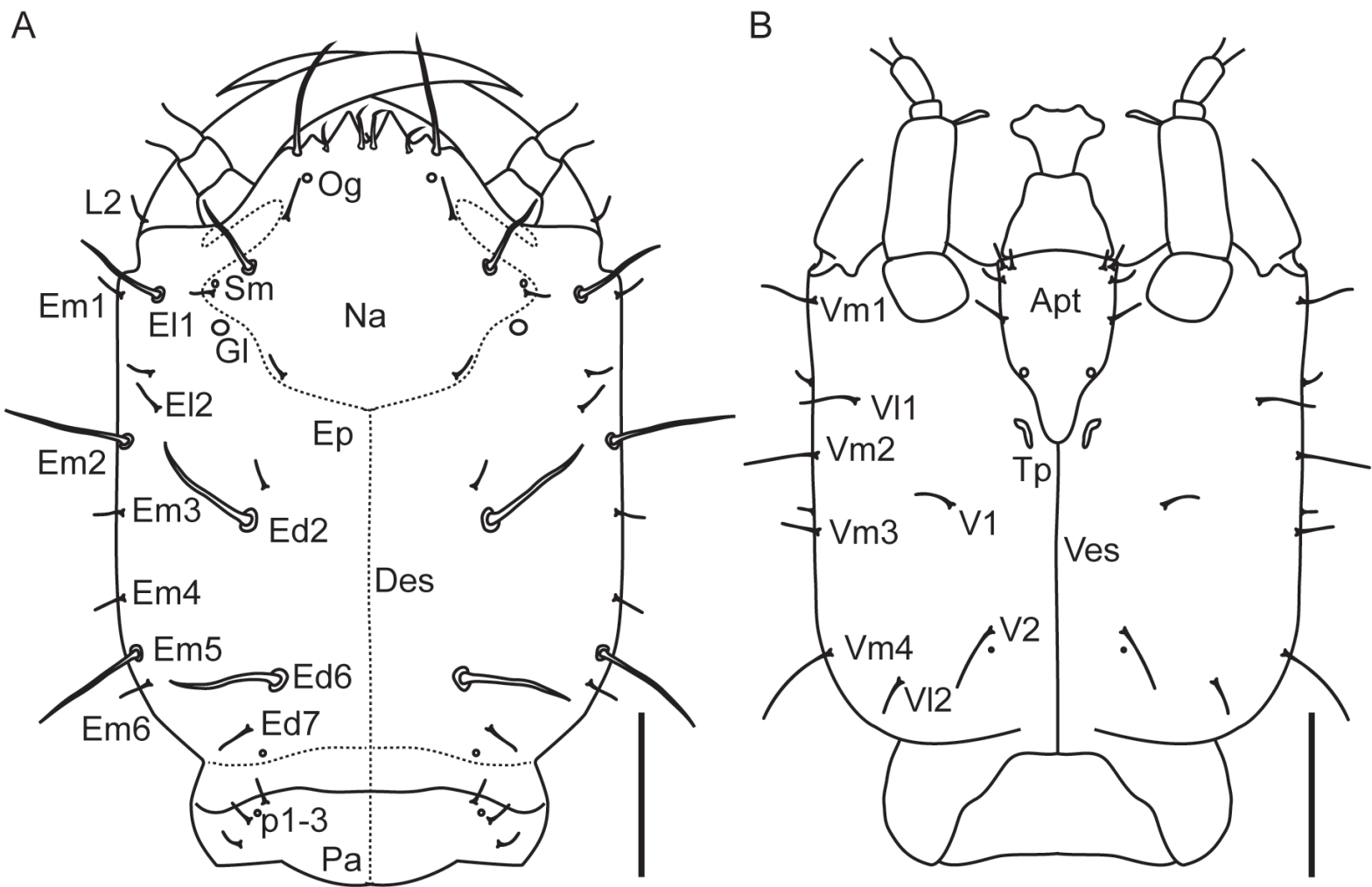

C

$\mathrm{D}$
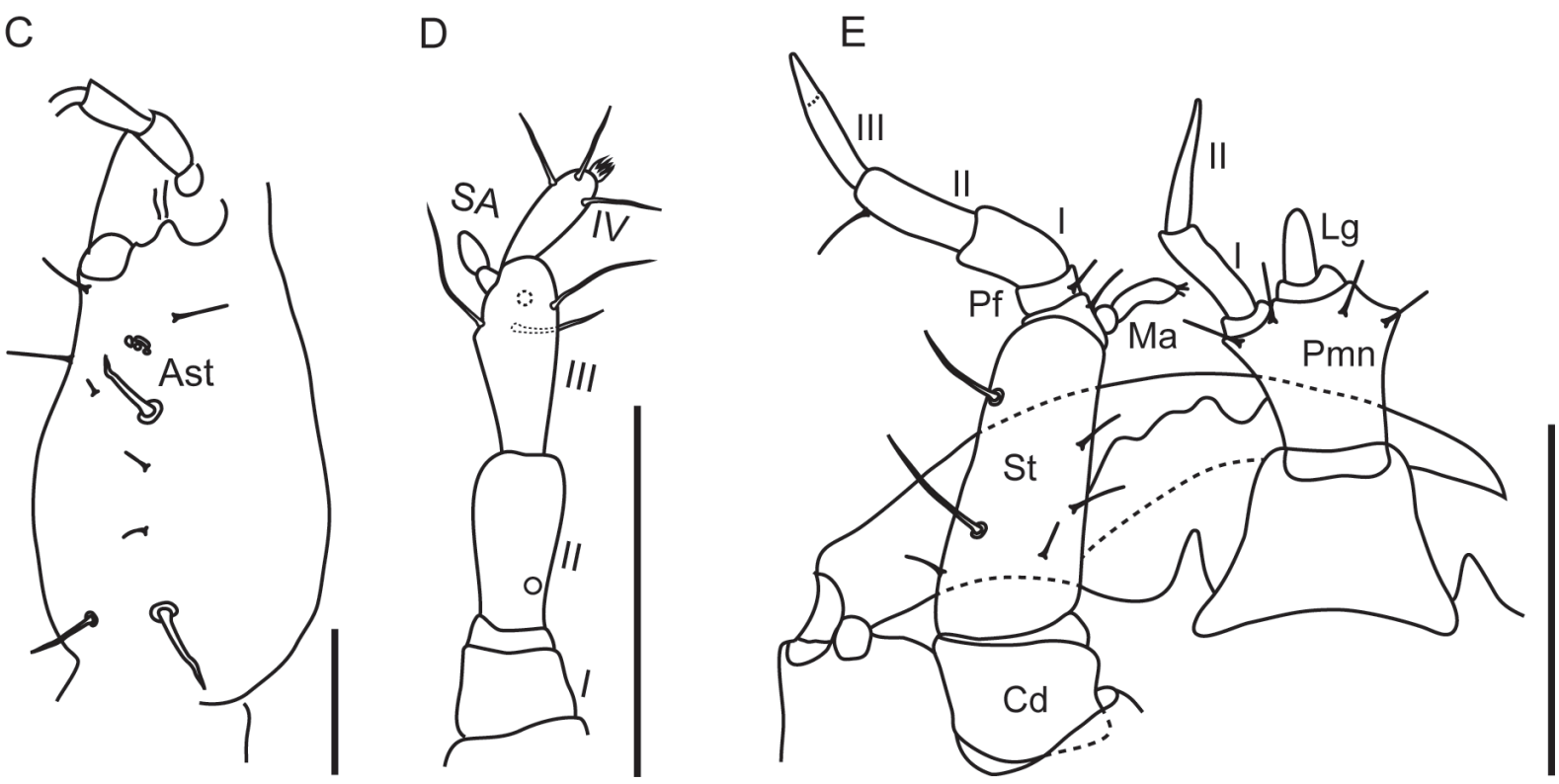

Fig. 6. Quedius masuzoi Watanabe, 1989. Morphology of larva: head. A. Head capsule, dorsal view. B. Head capsule, ventral view. C. Head capsule, lateral view. D. Antenna, dorsal view. E. Maxilla and labium, ventral view. Abbreviations: $\mathrm{Apt}=$ apotome; $\mathrm{Ast}=$ stemmata; $\mathrm{Cd}=$ cardo; $\mathrm{Des}=\mathrm{dorsal}$ ecdysial line; $\mathrm{Ed}=$ epicranial dorsal seta; $\mathrm{El}$ = epicranial lateral seta; $\mathrm{Em}=$ epicranial marginal seta; $\mathrm{Ep}=$ epicranial part; $\mathrm{Gl}=$ epicranial gland; $\mathrm{L}=$ lateral seta; $\mathrm{Lg}=$ ligula; $\mathrm{Ma}=$ mala; $\mathrm{Na}=$ nasale; $\mathrm{Og}=$ olfactory organ; $\mathrm{p}=$ posterior seta $\mathrm{Pa}=$ posterior area $\mathrm{Pf}=$ palpifer; $\mathrm{Pmn}=$ prementum; $\mathrm{Sa}=$ sensory appendage; $\mathrm{Sm}=$ sensilla; $\mathrm{St}=$ stipes; $\mathrm{Tp}=$ tentorial pit; $\mathrm{V}=$ ventral seta; Ves $=$ ventral ecdysial line; $\mathrm{Vl}=$ ventral lateral seta; $\mathrm{Vm}=$ ventral medial seta; $\mathrm{I}-\mathrm{IV}=$ segment enumeration. Scale bars $=0.5 \mathrm{~mm}$. 
We also found additional overlap in other ratio values and characters mentioned as differences between the two species by Smetana (1995). Specifically, the head width to length ratio varies in our conspecific material from 1.14 to 1.36 (Q. masuzoi 1.14 and Q. chiangi 1.10 in Smetana 1995). The ratio of length of temples to length of eyes varies from 4.27 to 7.33 (Q. masuzoi 4.73 and Q. chiangi 4.58 in Smetana $1995)$. The ratio of length to width of antennomere 4 varies from 0.75 to 1.6 (Q. masuzoi 1.09 and Q. chiangi $>1.09$ in Smetana 1995). The scutellum varies in the degree of punctation, with one specimen having it totally glabrous.

Noteworthy is that the female tergite X of $Q$. chiangi illustrated in Smetana (1995) has the same sclerotization pattern as in all females of $Q$. masuzoi that we examined, namely a heavier sclerotized

A

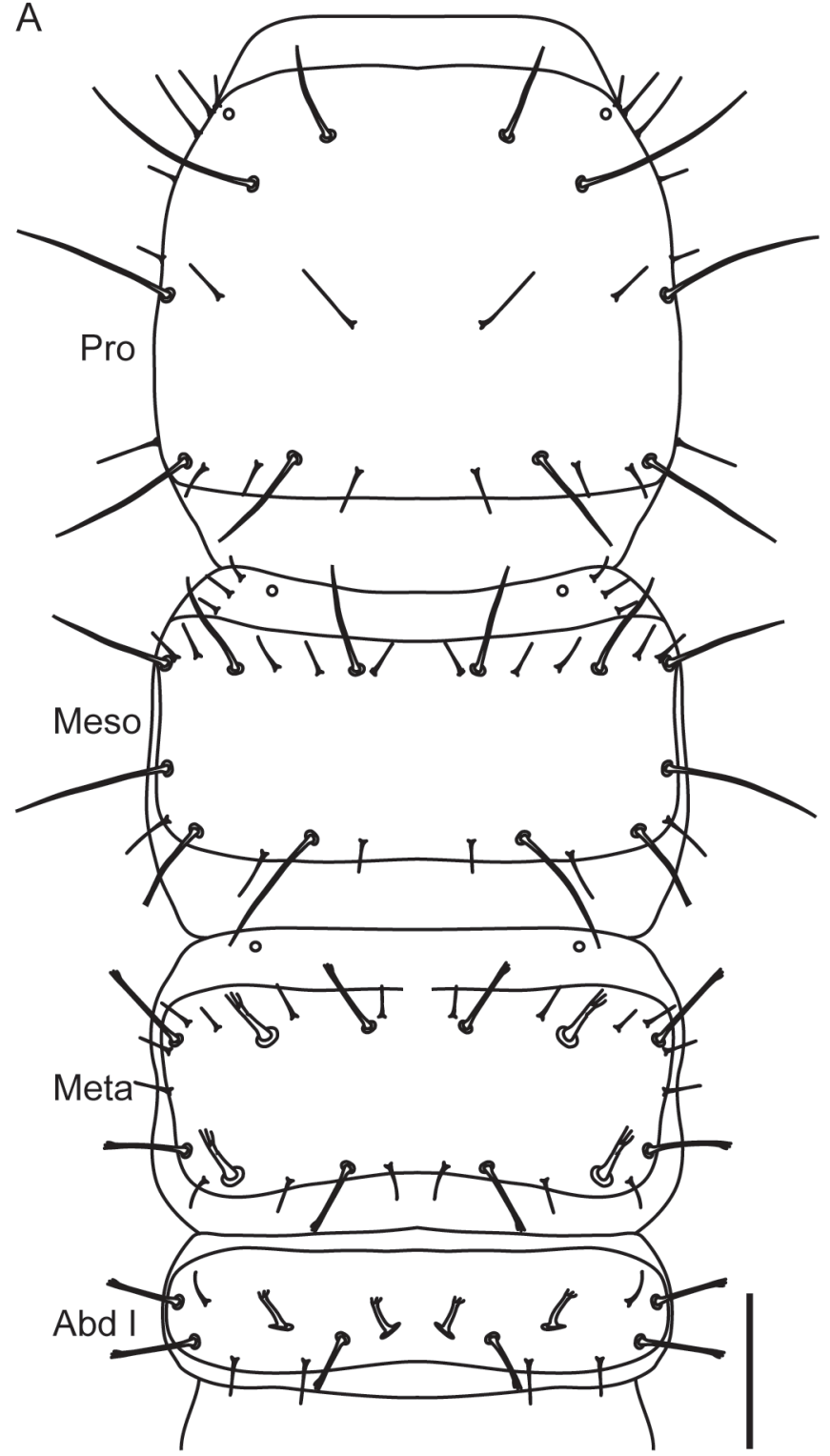

B

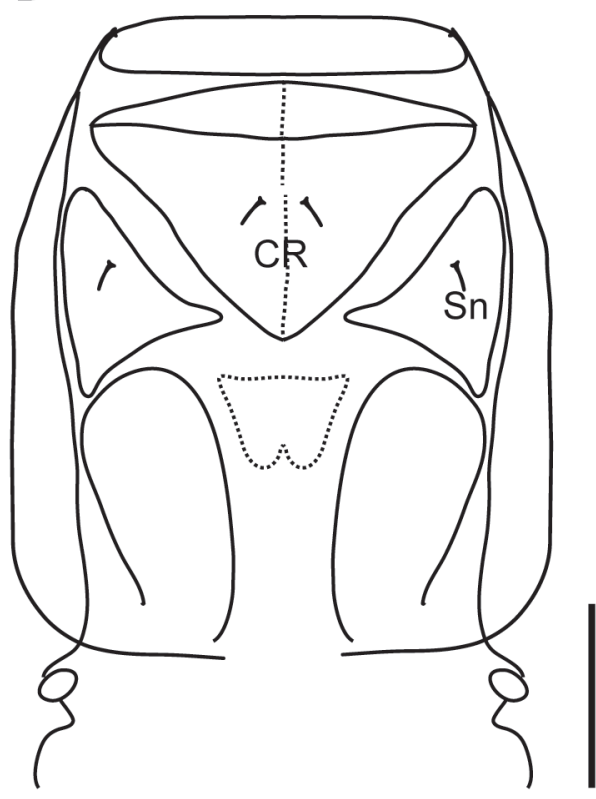

C

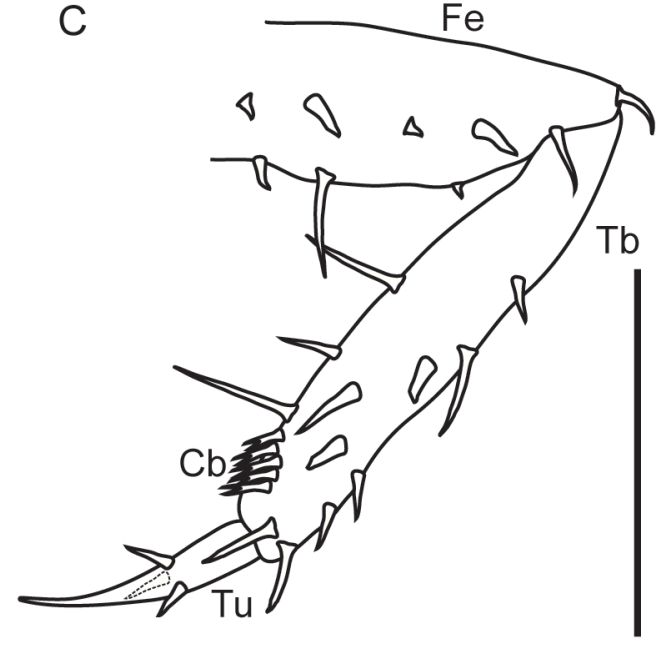

Fig. 7. Quedius masuzoi Watanabe, 1989. Morphology of larva: thorax and base of abdomen. A. Body fragment (thorax and abdominal segment I), dorsal view. B. Prothorax, ventral view. C. Anterior leg from anterior side. Abbreviations: Abd I = abdominal segment I; $\mathrm{Cb}=$ comb; $\mathrm{CR}=$ cervicosternum; $\mathrm{Fe}=$ femur; $\mathrm{Meso}=$ mesonotum; Meta $=$ metanotum; Pro = pronotum; $\mathrm{Sn}=$ sternite of prosternal area; $\mathrm{Tb}=$ tibia; $\mathrm{Tu}=$ tarsungulus. Scale bars $=0.5 \mathrm{~mm}$. 
apical area with a similar darker stalk connecting this area with the base of the tergite (Fig. 3G-H). Also, the geographic proximity of the type locality of $Q$. chiangi to the locality where additional material of Q. masuzoi was collected (Fig. 2) is noteworthy.

Examination of the holotype of $Q$. chiangi confirmed our thoughts, with all characters fitting within the explained variability, except for its size being slightly smaller. Based on all these considerations, we place $Q$. chiangi in synonymy with $Q$. masuzoi.

\section{Description (larva)}

The larva of $Q$. masuzoi (Fig. 5) possesses all the characters of the subfamily Staphylininae: toothed nasale (Fig. 6A); non-setose ligula (Fig. 6E); eyes of four stemmata each (Fig. 6C); anterior position of sensory appendage on antennal segment III (Fig. 6D); triangular cervicosternum with its apex projecting between proepisterna (Fig. 7B); and tarsungulus with three spines (Fig. 7C). It has 2-segmented labial palps and 3-segmented maxillary palps (Fig. 6E), relatively short urogomphi (about as long as pygopod) (Fig. 9C), frayed setae on the body (Figs 7A, 8) and combs of split (bifid) spines on anterior tibia (Fig. 7C), as in other Quediini. Overall, it fits the larval diagnosis of the genus Quedius given in Pietrykowska-Tudruj et al. (2014), which, however, was based on limited material. Based on the data in Pietrykowska-Tudruj et al. (2014) and our experience with larvae of other Staphylininae, we have above provided a diagnosis which should facilitate the separation of larvae of Q. masuzoi and related hypogean species from those of other Quedius or Quediini, supplemented by the following description.

A

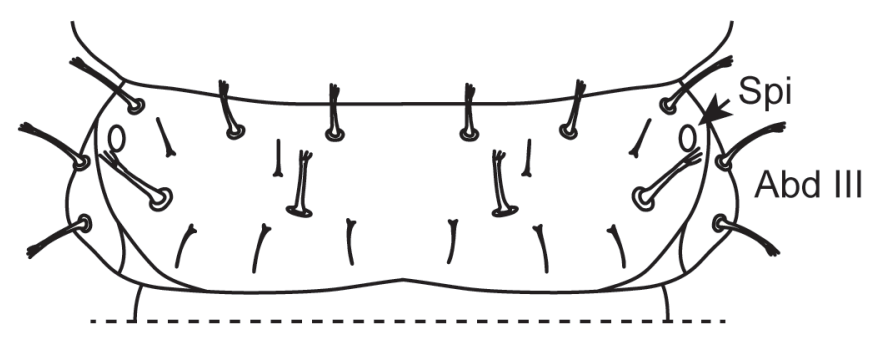

B

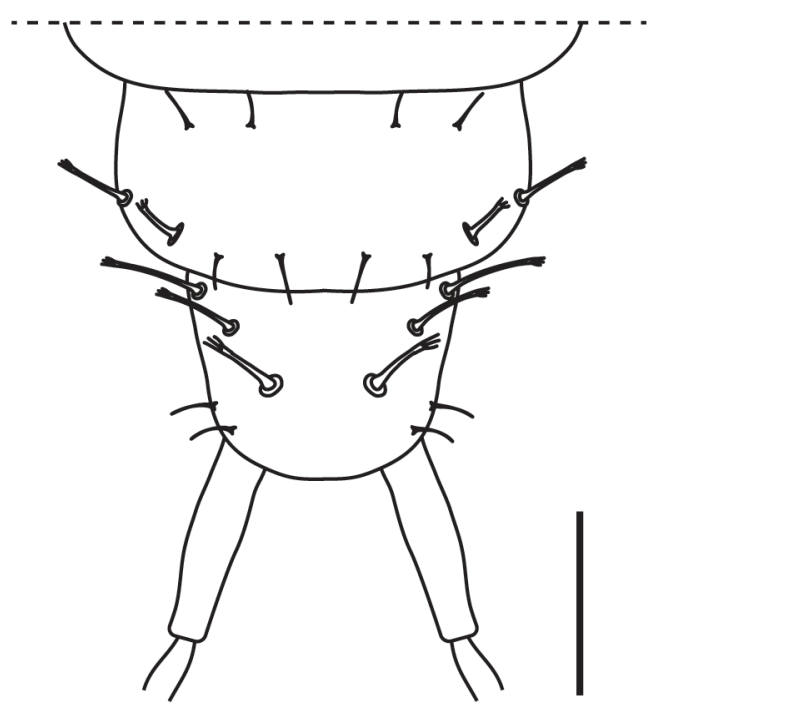

C

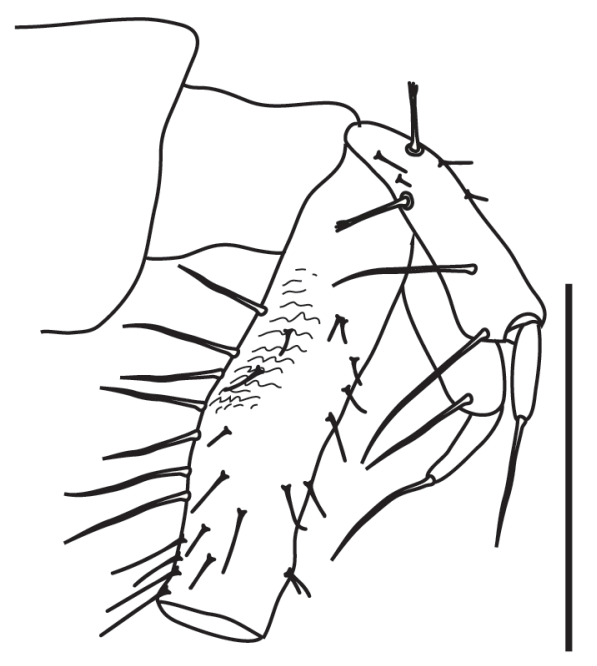

Fig. 8. Quedius masuzoi Watanabe, 1989. Morphology of larva: abdomen. A. Abdominal segment III, dorsal view. B. Apex of abdomen, dorsal view. C. Apex of abdomen, lateral view. Abbreviations: Abd $\mathrm{III}=$ abdominal segment III; Spi $=$ spiracle. Scale bars $=0.5 \mathrm{~mm}$. 
GENERAL. Body length 10-11 mm; head length $1.9-2.1 \mathrm{~mm}$, width $1.5-1.6 \mathrm{~mm}$; pronotum length $1.8-$ $1.9 \mathrm{~mm}$, width $1.5-1.7 \mathrm{~mm}$. Body slender, with relatively large head and long legs, prothorax as wide as parallel-sided head, meso- and metathorax, as well as basal four segments of abdomen; from segment IV abdomen gradually narrowing posteriad. Habitus as in Fig. 5, head capsule brownish, protergum, thorax and legs pale brown, abdomen whitish-grey, setae brown to dark brown. All macro- and microsetae of head, pro- and mesothorax and some setae on abdominal segments simple; few macrosetae on metathorax, the majority of those on abdomen, except pygopod, apically frayed (Figs 6-8).

HEAD. With broad but distinct neck, slightly longer than wide (Fig. 6A-B). Chaetotaxy of dorsal side of head as in Fig. 6A, as a pattern of larger and smaller simple setae, with distinct pair of epicranial glands $(\mathrm{Gl})$, and poorly visible small olfactory organs $(\mathrm{Og})$ and sensilla $(\mathrm{Sm})$ on nasale. Four pale stemmata (Ast) without pigment spots, in cluster on each side (Fig. 6C). Ventral side of head with chaetotaxy as in Fig 6B, with clearly visible tentorial pits (Tp) extended along short stalk of apotome (Apt). Antenna (Fig. 6D) 4-segmented, slender, segment III longer than segment II; segment II with one large 'pore' dorso-laterally; segment III with three macrosetae, large apically pointed sensory appendage (SA) and one 'pore' (ventrolateral); segment IV with three subapical macrosetae and a group of small setae and four solenidia apically. Nasale $(\mathrm{Na})$ with nine teeth at apical margin, with pair of paramedian teeth being the longest. Mandibles (Fig. 6A) slender, apically very sharp, with one large seta externally at base. Stipes of maxilla (Fig. 6E) with several macrosetae, two of them distinctly larger than others. Mala (Ma) finger-like, ca three times as long as wide at base (Fig. 6E). Palpifer (Pf) with one seta ventrally. Maxillary palp 3-segmented, its apical segment the longest, weakly subdivided into two pseudosegments. Labium (Fig. 6E) with well-sclerotized ventral side of prementum (Pmn), with four setae apically. Ligula (Lg) conical, ca two times as long as wide. Labial palps 2-segmented; segment II distinctly thinner and longer than I.

Thorax. Prothorax as long as wide, meso- and metathorax wider than long, of similar structure, metathorax slightly shorter than mesothorax; protergite with posterior carina, meso- and metatergite with anterior and posterior carinae (Fig. 7A). Pronotum and mesonotum with simple (not frayed) setae only; metanotum with larger setae frayed, smaller setae simple. Pro-, meso- and metanotum with smooth, glossy cuticle. Cervicosternum (CR) large, triangular, with pair of setae medially. Sternites of prosternal area (Sn) each with one seta (Fig. 7B).

LEGS. Relatively long, all of about the same length; femora with strong, long spines ventrally, tibia with similar spines dorsally and ventrally; tibial comb $(\mathrm{Cb})$ present on anterior legs only, consists of up to ten split (bifid) spines; rather long, apically very sharp tarsungulus (Tu) with three spines (Fig. 7C).

AbDOmen. Ten-segmented; only segment I with visible brownish glossy tergite and with distinct anterior carina; other segments without visible darker sclerites, whitish-grey. All abdominal segments with frayed setae, large and small, and with some simple small setae. Tergal chaetotaxy of segment I (Fig. 7A) simpler than on segments II-VIII (e.g., Fig. 8A of segment III), the latter having the same serially homologous pattern. Segment IX with reduced chaetotaxy (Fig. 8B), without laterosclerites and ecdysial line. Segment X (pygopod) with dense, long simple setae ventrally and short frayed setae dorsally, slightly longer than short urogomphi (measured without apical seta), the latter with few simple, frayed macrosetae, each with one long, frayed apical macroseta (Fig. 8C).

\section{Note}

The lack of notable pigmentation of the stemmata and the relatively long legs are apparently adaptations to the hypogean environment during the larval stage. 


\section{Molecular results and identity of the new material}

We sequenced the $\mathrm{CO} 1$ barcode for six specimens (four adults and two larvae) of the putative Q. masuzoi from the same locality, a subterranean water diversion channel at Mt Shi (Fig. 9). All larvae and adults showed matching $\mathrm{CO} 1$ barcodes, supporting the idea that they are conspecific. There were no ambiguous sites within the six barcoded individuals, and thus the dissimilarity between them equals 0.000 (Fig. 10). The two species, Q. mesomelinus and Q. scitus, used as outgroup, showed a 0.131 dissimilarity to our

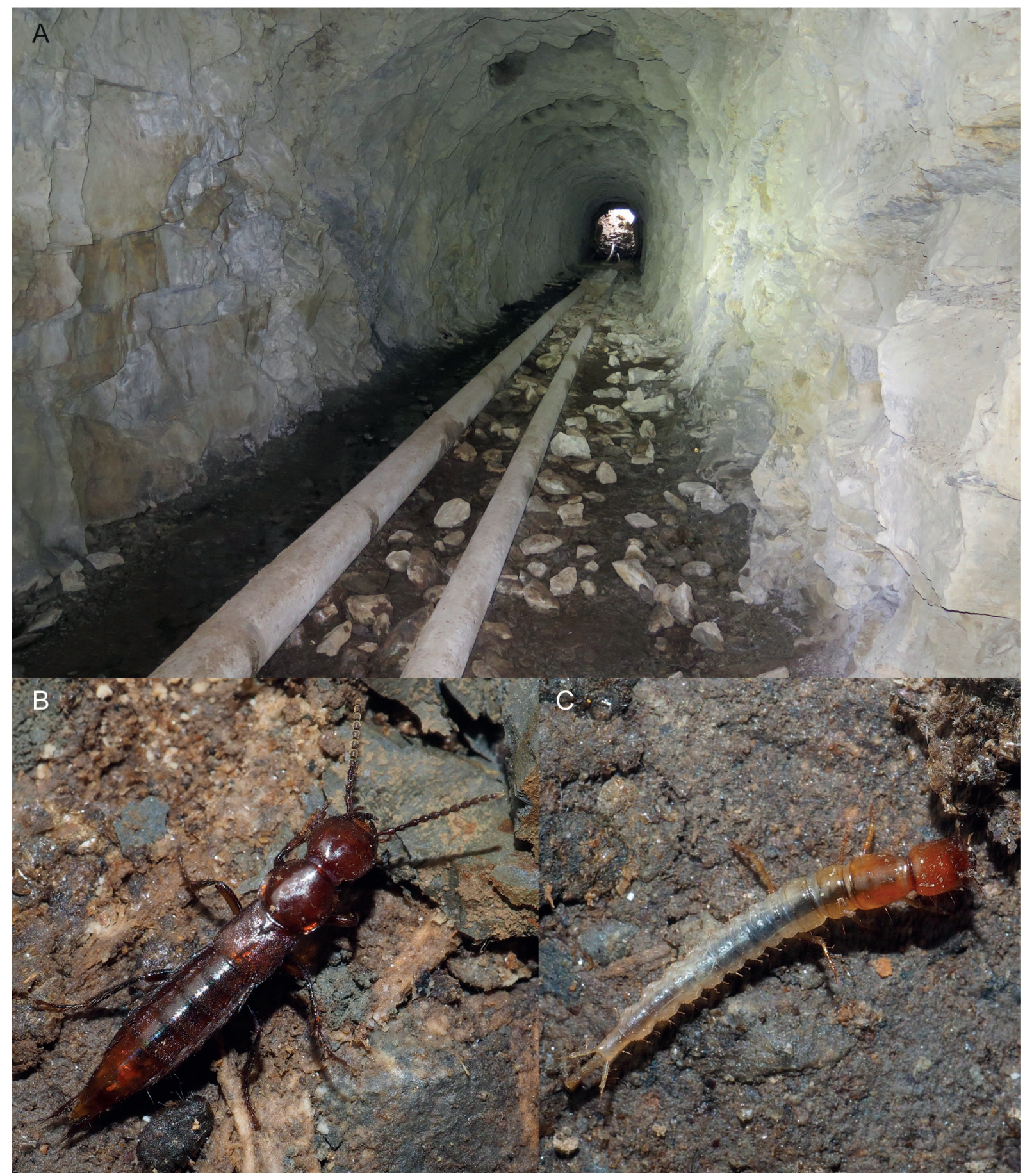

Fig. 9. Photographs of collection site and live specimens of Quedius masuzoi Watanabe, 1989. A. Habitat of newly collected specimens reported in this paper. B. Adult. C. Larva. 
samples of Q. masuzoi and a dissimilarity of 0.115 between each other. They also showed larger within species dissimilarity compared to Q. masuzoi ( 0.007 in Q. mesomelinus and 0.002 in Q. scitus). The larger within species dissimilarity in the outgroup species is probably due to the larger geographic range of the sampled specimens. All our putative $Q$. masuzoi samples were from the same site and collecting event, whereas samples for the outgroup species from GenBank come from multiple localities which are geographically remote from one another. Aedeagi were identical in all five males in the sample of our newly collected material and fully match the illustrations of the aedeagus of $Q$. masuzoi in Watanabe (1989) and Smetana (1995), reliably identifying our specimens as that species (Fig. 3A-B, D-E).

\section{Distribution}

This species is known from three localities: from Mt Neng-kao-pei-feng in northeastern Taiwan (type locality of Q. masuzoi), as well as from Pai-Yun Hut, Yushan National Park (type locality of Q. chiangi) and nearby Mt Shi (newly collected material) in the central part of the island (i.e., from Nantou and Chiayi Counties) (Fig. 2).

\section{Bionomics}

The holotype of Q. masuzoi was dug out from loose rocks with poor vegetation (Watanabe 1989). For $Q$. chiangi, the holotype was collected from an old rocky wall, while the collecting circumstances of the paratype remain unknown (Smetana 1995). The additional specimens of $Q$. masuzoi reported here were collected from a short subterranean tunnel (Fig. 9A) close to the type locality of $Q$. chiangi. The rocky walls of the tunnel were covered by bat guano and its entrance opens to a primary forest. Adults

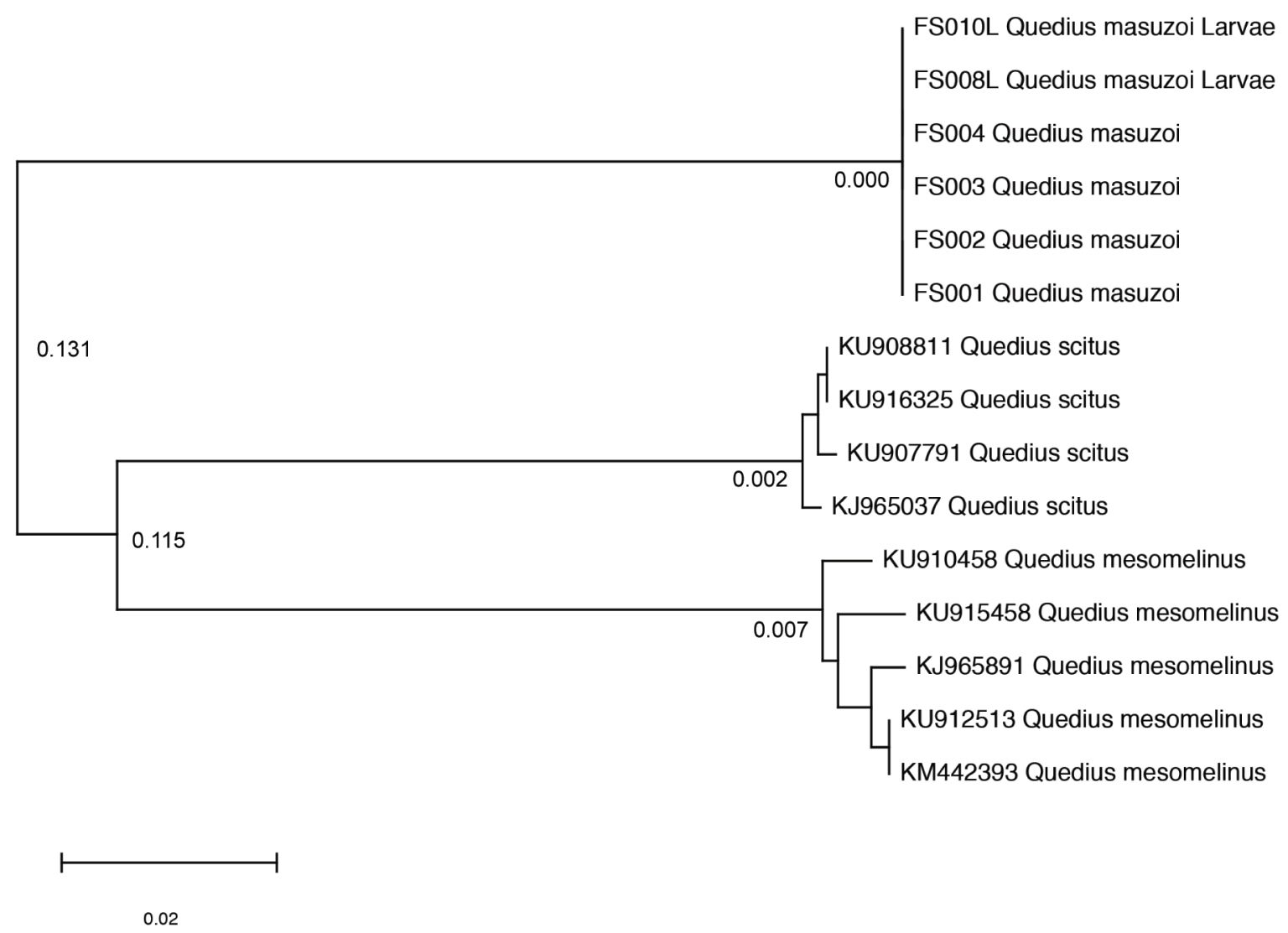

Fig. 10. Maximum likelihood species tree of $\mathrm{CO} 1$ barcodes. The sequences of Quedius masuzoi Watanabe, 1989 were produced in this study. Sequences of Quedius scitus (Gravenhorst, 1806) and Quedius mesomelinus (Marsham, 1802) are from GenBank. Numbers represent within (on branch) and between (at node) species dissimilarity of CO1 barcodes. 
were observed both on the surface of the ground and under the rocks of the tunnel (Fig. 9B). Larvae (Fig. 9C) were collected under rocks in the same tunnel, during the same collecting event. Leiodidae spp, other rove beetles belonging to Xantholinini (all Coleoptera), Rhaphidophoridae sp. (Orthoptera) and Nycteribiidae sp. (Diptera) were found in the same tunnel. The collected adults and larvae of Q. masuzoi were kept in the laboratory for over two weeks, where they were fed with both live and dead Rhaphidophoridae sp., Blatta lateralis Walker, 1868 (Blattodea) and Odontotermes formosanus (Shiraki, 1909) (Blattodea). Despite being supplied with live prey, both adults and larvae fed on dead prey only, i.e. they did not display predatory behaviour in the laboratory. Unfortunately, we did not rear any adults from the collected larvae and no other significant observations on their behaviour were made.

\title{
Remarks
}

The holotype of $Q$. chiangi is in good condition, mounted on a card. Segment 3-4 of the left maxillary palpus, antennomeres 4-11 of left antenna, the left fore claw, and the left hind tibia and femur are missing. The genital segment was dissected and sealed using Euparal, placed on a plastic card pinned underneath the paper card.

Quedius nishikawai Watanabe, 1991

Figs 2, 3I, 4B

Quedius nishikawai Watanabe, 1991: 225, fig. 6 (description; type locality: S Taiwan, Mt Pei-ta-wu Shan [北大武山], alt. 2520 m, Tai-wu Hsiang, P'ing-tung Hsien).

Quedius nishikawai-Smetana 1995: 48, fig. 55 (redescription).

\section{Diagnosis}

Quedius nishikawai is quite similar with Q. masuzoi (Fig. 4) but, according to Watanabe (1991) and Smetana (1995), it can be distinguished from the latter at least by the larger and more robust body, with broader head and elytra, the longer antennae with notably longer antennomeres 8-10 and by the presence of minute punctation on the head. Based on the newly discovered females for Q. masuzoi, we can add that the female of $Q$. nishikawai differs from that of the former species by its tergite $\mathrm{X}$, which does not have the distinct stalk connecting the other heavier sclerotized apical and basal areas of the tergite (compare Fig. 3I and 3G-H).

\section{Description}

\author{
Male \\ Unknown. \\ Female \\ See Watanabe (1991) and Smetana (1995).
}

\section{Distribution}

Known only from the type locality in Pingtung County, S Taiwan (Fig. 2).

\section{Bionomics}

Nothing is known about the bionomics of this species, except that it was collected at a high elevation, similarly to other members of the abnormalis group in Taiwan.

\section{Remarks}

Quedius nishikawai remains known only from the single female (Fig. 4B) that the original description (Watanabe 1991) and later redescription (Smetana 1995) were based on. As can be seen from the case 
of Q. masuzoi above, the external characters used for species delimitation in this group turned out to be quite variable, even among clearly conspecific specimens from the same locality. Also, based on the case of Q. masuzoi and some other non-Taiwanese hypogean species studied in Solodovnikov \& Hansen (2016) and Salnitska \& Solodovnikov (2018), we can see that the distributions of hypogean species may not be that locally restrained, contrary to common assumptions made by systematists about very low dispersal abilities in such species and high levels of local endemism. Therefore, in view of the data presented in this paper, the status of $Q$. nishikawai as a separate species remains unclear until males are found. Given at least a distinct difference between $Q$. nishikawai and $Q$. masuzoi in the sclerotization pattern of the female tergite $X$ (Fig. 3), the species status of for the former is justified at the moment.

Quedius adilus sp. nov.

urn:1sid:zoobank.org:act:2C75AA2D-F524-4308-9823-186131633E08

Figs 2, 3C, F, 11

\section{Etymology}

The species name adilus is derived from the Greek word 'á $\delta \eta \lambda o \varsigma$ ', which means 'latent', 'existing or present but concealed'. This name hints at the difficulty of collecting this species, which is hidden in hypogean crevices.

\section{Material examined}

Holotype

TAIWAN • đ’; Nantou County, Yuanfeng [鳥峰]; 6 Apr 2004-11 May 2004; C.S. Lin and W.T. Yang leg.; "Malaise trap (KCN) / Quedius (Microsaurus) sp. Det. A. Brunke 2018"; "NMNS ENT, 6660241"; NMNS.

Since the originally pinned holotype was remounted on a card in this study, its pronotal disc on the left side bears a hole from the pin. The genital segment and aedeagus were dissected and preserved in glycerin in a microvial pinned with the card. The last segment of the right antenna, as well as the middle and posterior tibiae, are missing.

\section{Description}

\section{Male}

Measurements. HW: 2.47, HL: 2.12, HW/HL ratio: 1.17, TL/EL ratio: 7, PL: 2.54, PW: 2.83, PL/PW ratio: $0.90, \mathrm{~A} 4 \mathrm{~L} / \mathrm{A} 4 \mathrm{~W}$ ratio: 1.25 , total body length: 14.46 , body length without terminalia: 11.05 .

HaBitus. Dark brown-reddish, with paler apical part of antenna, tibia and tarsi (Fig. 11A). Large species, dorso-ventrally flattened, with very small eyes and long legs.

HEAD. Large, slightly wider than long, flattened and with oblique longitudinal ridge behind eyes; two basal punctures on each side (apical one is smaller) and five additional punctures near basal punctures. Antennae long and slender; antennomeres 4-10 more or less spherical.

Thorax. Pronotum distinctly narrowing anteriad; dorsal rows each with three punctures; left sublateral row with two punctures; right sublateral row with three punctures; one additional puncture between left dorsal and sublateral rows of punctures; two additional punctures between right dorsal and sublateral rows of punctures. Scutellum sparsely punctured. Elytra shorter than pronotum; hind wings absent.

LEGS. First four segments of tarsus strongly dilated.

ABDOMEN. Sternite VIII broad and sub-parallel, with distinct medial emargination apically and five setiferous punctures present at each lateral side. Sternite IX basally slightly oval, apically emarginate. Tergite $\mathrm{X}$ with distinct emargination basally, with several setae apically. 
Aedeagus (Fig. 3C, F, 11B-C). Median lobe slightly broader than paramere, apically protruding over paramere (in parameral view), slightly sharpened apically, its subapical protrusion axe-like in lateral view; paramere large, apically bilobed, each lobe with four long apical setae and sparse sensory peg setae, apical part of paramere slightly narrower than basal part.

\section{Female}

Unknown.

\section{Differential diagnosis}

This new species is similar to $Q$. masuzoi and $Q$. nishikawai, from which it differs in the more dorsoventrally flattened head, with an oblique longitudinal ridge behind the eyes. Also, unlike both these

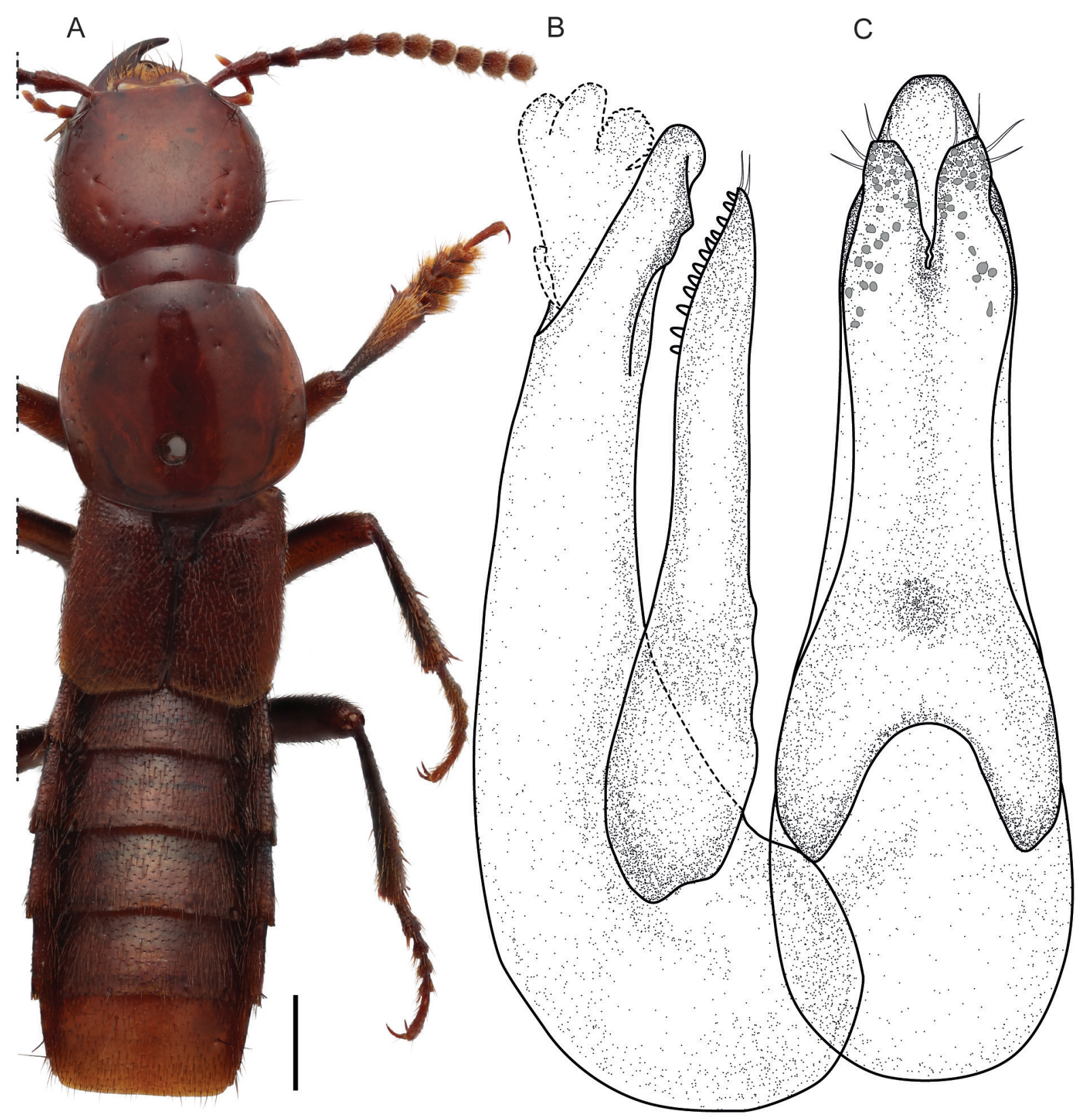

Fig. 11. Quedius adilus sp. nov. A. Habitus, legs and antennae of left side cropped out of image to preserve space. B. Aedeagus in lateral view. C. Aedeagus in parameral view. Scale bar: A=1 mm. 
species, Quedius adilus sp. nov. has two basal punctures on each side, instead of the usual one, and numerous (five) additional punctures near each basal puncture. Its antennomeres 4-10 are rather spherical and antennomeres 8-10 are relatively shorter than in Q. nishikawai. As these characters seem to be highly variable within this species group, reliable identification of the new species should be made through an examination of the male genitalia. Unlike in Q. masuzoi, the median lobe in Quedius adilus sp. nov. is more narrowly elongate and forms a sharper point at the apex; it strongly protrudes over the apical margin of the bilobed paramere (in parameral view) (compare Fig. 3C and 3A-B); the elevated dents of its subapical carina are positioned more remotely from its apex (in lateral view) (compare Fig. 3F and 3D-E). Also, compared to conditions in Q. masuzoi, the split between the apical lobes of the paramere in Quedius adilus sp. nov. is more narrow and the arrangement of the sensory peg setae is more sparse (Fig. 11B-C).

\section{Distribution}

Known only from the type locality in Nantou County in central Taiwan (Fig. 2).

\section{Bionomics}

The holotype was collected by Malaise trap, probably accidentally. No information about the habitat is provided on the locality label.

\section{Remarks}

As established in this paper, the aedeagus shape in $Q$. masuzoi is stable, contrary to other characters earlier chosen to delimit that species. Therefore, the clearly visible difference in the shape of the aedeagus between $Q$. adilus sp. nov. and Q. masuzoi, in addition to several external characters separating the new species from $Q$. nishikawai, advocate for its formal description even based on the available singleton. The type locality (Yuangfeng) of the new species is only $10 \mathrm{~km}$ away from Nanhua Mt, the type locality of $Q$. masuzoi (Fig. 2), which signals that the two species may be sympatric, further corroborating our hypothesis that the aedeagal difference we observe is indicative of a new species different from Q. masuzoi.

\section{Discussion}

While working on this paper we faced the problem that all three hitherto known very similar species were described based on very limited material. Moreover, two of them were known based only on females which posed additional difficulties because, as proven by decades of taxonomic practice, the aedeagus is the best and sometimes the only source of species-specific characters. At the same time, the species of this group, because of their subterranean biology, are very rare in the collections, prompting systematics to make taxonomic decisions based on such fragmentary material. For example, Watanabe (1989) refrained from describing a species based on a single female, stating that: "Members of this species-group are usually very similar to one another in general appearance, and can be identified with confidence only on their male genitalia." However, he shortly after disregarded his own suggestion and described $Q$. nishikawai based on a single female (Watanabe 1991). The paucity of material has not previously allowed an assessment of the variability of characters chosen for species delimitation in this group to be made.

Based on the new serial material studied here with both molecular and morphological approaches, we revealed a significant intraspecific variation in these external characters, especially chaetotaxy, since they varied even within a sample of specimens from the same collection event (i.e., same day and locality). This is congruent with similar findings for other species of Quedius with or without hypogean biology. For example, the hypogean Quedius roma Solodovnikov \& Hansen, 2016 has a varying number of setiferous pores in the lateral and sublateral rows of the pronotal disc (Solodovnikov \& Hansen 2016). 
Additionally, its body size ranges from 9.0 to $11.5 \mathrm{~mm}$ and colouration varies from nearly blackish to pale brown. The mutilatus group, recently studied in Salnitska \& Solodovnikov (2018), is another example where significant variability within hypogean species has been noted. Various other studies stress the high intraspecific variability of morphological characters in other, non-hypogean species of Quedius (Solodovnikov 2002a, 2002b; Assing 2017, 2018) and in various Staphylinidae (e.g., Puthz 1981; Assing 2005).

An additional factor confusing the taxonomy of this group was the assumption that similar hypogean specimens found at various mountain tops or ranges, or at some distance from each other, belonged to different species because they must have small distribution ranges, as they are wingless and confined to restricted microhabitats of cracks and crevices of talus at higher elevations. This hypothesis, however, was never explored in depth for any of these species and, on the contrary, several such apterous, microphthalmous hypogean species seem to occur across large areas, e.g., Quedius przewalskii Reitter, 1887, Quedius moeris Smetana, 1995, Quedius equus Smetana, 1994, Quedius mutilatus Eppelsheim, 1888 (see distribution maps in Solodovnikov \& Hansen 2016; Salnitska \& Solodovnikov 2018). Due to the lack of any in-depth studies, it is still unclear whether these seemingly continuously variable widespread hypogean Quedius would constitute the same species by molecular standards and, if so, how they maintain such large distributions. It may well be that these broad distributions are an artefact of our rough approach to the morphological variability, where we notice a hiatus between 'species' only when it is easy to see with the 'naked eye'.

Ideally, a larger series and dense sampling are necessary for a robust taxonomic exploration of these beetles. This is hard or impossible to achieve due to their cryptic life history. Therefore, at least a combined approach (morphological and molecular as we tried here) should be practised whenever possible. Also, we hope that the larval description of $Q$. masuzoi will increase the chances of collecting these rare beetles if both adult and immature stages are considered.

As it looks now, all three Taiwanese hypogean species studied here are phylogenetically very close to each other and, based on their aedeagal and external similarity, likely form a monophyletic group with at least some species of the current abnormalis group from Japan. This is an interesting disjunction which could be better examined after an in-depth inventory of the hypogean Quedius of Taiwan and Japan and the reconstruction of their time-calibrated phylogeny.

Although many examples of transoceanic dispersal events for terrestrial animals are known, e.g., the rafting of flightless weevils to Lanyu Island in eastern Taiwan (Yeh et al. 2018), it is unlikely for species with such a specialised ecology as members of the abnormalis group. Therefore, it seems more likely that this group, now restricted to Japan and Taiwan, is of older origin, when the respective islands were linked by the Taiwan-Sinzi Folded Zone around the Middle Oligocene and Middle Miocene (Kong et al. 2000). A similar case of dispersal from Southwestern Japan to Taiwan using the Taiwan-Sinzi Folded Zone has been hypothesized for salamanders (Li et al. 2011). Interestingly, these salamanders are, like the members of the Q. abnormalis group, restricted to the high mountain areas of Taiwan where they, like the rove beetles, are found in hypogean habitats.

\section{Acknowledgements}

The authors gratefully acknowledge Yu-Ta Lai for providing information and the specimens of Quedius masuzoi. We thank Wei-Ren Liang for photographing the larvae. We also thank Bin-Hong Ho, HsingChe Liu and Wei-Ren Liang for their help during the field trip. We are also indebted to the curators mentioned above, especially Shuhei Nomura for providing images of the types of $Q$. nishikawai and Q. masuzoi. We are grateful to Alfred Newton for providing useful references. AKH thanks the Danish Ministry for Culture's Research Fund (KFU grant FORM.2018-0006) for financial support. 


\section{References}

Assing V. 2005. A revision of the genus Leptobium Casey (Coleoptera: Staphylinidae: Paederinae). Stuttgarter Beiträge zur Naturkunde, Series A (Biologie) 673: 1-182.

Assing V. 2017. On Quedius coloratus Fauvel, 1875 and allied species, with an appendix on Quedius species collected in Greece with subterranean pitfall traps, and a new synonymy (Coleoptera: Staphylinidae: Staphylininae). Linzer Biologische Beiträge 49 (1): 207-228.

Assing V. 2018. On the taxonomy and zoogeography of some west Palaearctic Quedius species, with a focus on the east Mediterranean and the species allied to Quedius umbrinus and Q. nivicola (Coleoptera: Staphylinidae: Staphylininae). Linzer Biologische Beiträge 50: 149-182.

Brunke A.J., Chatzimanolis S., Schillhammer H. \& Solodovnikov A. 2016. Early evolution of the hyperdiverse rove beetle tribe Staphylinini (Coleoptera: Staphylinidae: Staphylininae) and a revision of its higher classification. Cladistics 32: 427-451. https://doi.org/10.1111/cla.12139

Culver D.C. 1982. Cave Life: Evolution and Ecology. Harvard University Press, Cambridge, MA.

Folmer O., Black M., Hoeh W., Lutz R. \& Vrijenhoek R. 1994. DNA primers for amplification of mitochondrial cytochrome coxidase subunit I from diverse metazoan invertebrates. Molecular Marine Biology and Biotechnology 3 (5): 294-299. https://doi.org/10.2307/1309296

Hadley A. 2010. CombineZP. Available from http://combinezp.software.informer.com/download/ [accessed 10 May 2020].

Kong F., Lawver L.A. \& Lee T.-Y. 2000. Evolution of the southern Taiwan-Sinzi Folded Zone and opening of the southern Okinawa trough. Journal of Asian Earth Sciences 18: 325-341.

https://doi.org/10.1016/s1367-9120(99)00062-0

Kumar S., Stecher G., Li M., Knyaz C. \& Tamura K. 2018. MEGA X: Molecular Evolutionary Genetics Analysis across computing platforms. Molecular Biology \& Evolution 35 (6): 1547-1549.

https://doi.org/10.1093/molbev/msy096

Li J., Fu C. \& Lei G. 2011. Biogeographical consequences of Cenozoic tectonic events within East Asian margins: a case study of Hynobius biogeography. PLoS One 6 (6): 1-10.

https://doi.org/10.1371/journal.pone.0021506

Pietrykowska-Tudruj E., Staniec B. \& Solodovnikov A. 2011. Discovery of the Quedius antipodum Sharp larva from New Zealand: phylogenetic test of larval morphology for Staphylinini at the intratribal level (Coleoptera: Staphylinidae). Systematic Entomology 37: 360-378.

https://doi.org/10.1111/j.1365-3113.2011.00612.x

Pietrykowska-Tudruj E., Czepiel-Mil K. \& Staniec B. 2014. Larval morphology of selected Quedius Stephens, 1829 (Coleoptera: Staphylinidae: Staphylinini) with comments on their subgeneric affiliation. Zootaxa 3827 (4): 493-516. https://doi.org/10.11646/zootaxa.3827.4.4

Puthz V. 1981. On some species of the genus Stenus Latreille from Taiwan, including descriptions of new species, a key to the East Asiatic representative of the comma-group, and a checklist of species known from Taiwan (Coleoptera, Staphylinidae). $172^{\text {nd }}$ contribution to the knowledge of Steninae. Fragmenta Coleopterologica 29/32: 115-124.

Salnitska M. \& Solodovnikov A. 2018. Taxonomy of the poorly known Quedius mutilatus group of wingless montane species from Middle Asia (Coleoptera: Staphylinidae: Staphylinini). European Journal of Taxonomy 401: 1-17. https://doi.org/10.5852/ejt.2018.401

Smetana A. 1995. Revision of the tribes Quediini and Tanygnathinini. Part III. Taiwan. (Coleoptera: Staphylinidae). National Museum of Natural Science, Taichung City, Special Publication 6: 1-145. 
Smetana A. 1996. Revision of the tribes Quediini and Tanygnathinini. Part III. Taiwan. (Coleoptera: Staphylinidae). Supplement I (Coleoptera: Staphylinidae). Bulletin of the National Museum of Natural Science 8: 23-28.

Smetana A. 2001a. Revision of the subtribe Quediina and the tribe Tanygnathinini. Part III. Taiwan (Coleoptera: Staphylinidae). Supplement II. Sukunahikona. Special Publication of the Japan Coleopterological Society, Osaka 1: 55-63.

Smetana A. 2001b. Contribution to the knowledge of the Quediina (Coleoptera, Staphylinidae, Staphylinini) of China. Part 20. Genus Quedius Stephens, 1829. Subgenus Microsaurus Dejean, 1833. Section 12. Elytra, Tokyo 29 (1): 193-216.

Smetana A. 2019. Revision of the tribes Quediini and Tanygnathinini. Part III. Taiwan. (Coleoptera: Staphylinidae). Supplement III (Coleoptera: Staphylinidae). Studies and Reports, Taxonomical Series 15 (1): 231-238.

Solodovnikov A.Y. 2002a. Taxonomy and faunistics of some species of Quedius Stephens, 1829 from the Caucasus and Asia Minor. Koleopterologische Rundschau 72: 137-158.

Solodovnikov A.Y. 2002b. A remarkable pair of syntopic nidicolous sibling species of Quedius Stephens, 1829 from the Caucasus (Coleoptera: Staphylinidae: Staphylininae). Russian Entomological Journal 11 (3): 265-272.

Solodovnikov A. \& Hansen A.K. 2016. Review of subterranean Quedius, with description of the first hypogean species from the Russian Far East (Coleoptera: Staphylinidae: Staphylinini). Zootaxa 4170 (3): 475-490. https://doi.org/10.11646/zootaxa.4170.3.3

Solodovnikov A.Y. \& Newton A.F. 2005. Phylogenetic placement of Arrowinini trib. n. within the subfamily Staphylininae (Coleoptera: Staphylinidae), with revision of the relict South African genus Arrowinus and description of its larva. Systematic Entomology 30: 398-441.

https://doi.org/10.1111/j.1365-3113.2004.00283.x

Uéno S.-I. \& Watanabe Y. 1966. The subterranean staphylinid beetles of the genus Quedius from Japan. Bulletin of the National Science Museum, Tokyo 9 (3): 321-337.

Uéno S.-I. \& Watanabe Y. 1970. More cave species of the genus Quedius (Coleoptera, Staphylinidae) from Japan. Bulletin of the National Science Museum, Tokyo 13 (1): 9-20.

Vandel A. 1964. La Biologie des Animaux cavernicoles. Gauthier-Villars, Paris. https://doi.org/10.2307/2674

Watanabe Y. 1981. A new species of Quedius (Coleoptera, Staphylinidae) from a tuff cave in central Japan. Journal of the Speleological Society of Japan 6: 19-22.

Watanabe Y. 1986. Two new Quedius (Coleoptera, Staphylinidae) from the upper hypogean zone of central Honshu, Japan. Journal of the Speleological Society of Japan 11: 19-25.

Watanabe Y. 1987. Quedius yasuhikoi and its new relatives (Coleoptera, Staphylinidae). Kontŷu, Tokyo 55 (2): $324-332$.

Watanabe Y. 1989. Two Taiwanese staphylinid beetles related to Quedius abnormalis (Coleoptera, Staphylinidae). Elytra, Tokyo 17 (2): 169-174.

Watanabe Y. 1990. New endogean species of the group of Quedius abnormalis (Coleoptera, Staphylinidae) from central Honshu, Japan. Journal of the Speleological Society of Japan 15: 26-33.

Watanabe Y. 1991. Two new apterous staphylinids (Coleoptera, Staphylinidae) from Taiwan. Elytra, Tokyo 19 (2): 221-228. 
Watanabe Y. 2000. A new species of the group of Quedius abnormalis (Coleoptera, Staphylinidae) from the northern Japanese Alps, central Japan. Journal of the Speleological Society of Japan 25: 45-49.

Watanabe Y. 2008. A new subterranean species of the genus Quedius (Coleoptera, Staphylinidae) from central Honshu, Japan. Journal of the Speleological Society of Japan 33: 28-32.

Watanabe Y. 2009. A new species of Quedius abnormalis (Coleoptera, Staphylinidae) from Mt. Kisokomagatake in central Honshu, Japan. Journal of the Speleological Society of Japan 34: 15-21.

Watanabe Y. \& Yoshida M. 1970. Two new species of the subterranean Quedius (Coleoptera, Staphylinidae) from Shikoku, Japan. Bulletin of the National Science Museum, Tokyo 13 (1): 1-8.

Watanabe Y. \& Yoshida M. 2008. Two new species of the group of Quedius abnormalis (Coleoptera, Staphylinidae) from Eastern Shikoku, Japan. Japanese Journal of Systematic Entomology 14 (2): 135140 .

Yeh H.-Y., Tseng H.-Y., Lin C.-P., Liao C.-P., Hsu J.-Y. \& Huang W.-S. 2018. Rafting on floating fruit is effective for oceanic dispersal of flightless weevils. Journal of Experimental Biology 221: 1-8.

https://doi.org/10.1242/jeb.190488

Manuscript received: 31 January 2020

Manuscript accepted: 16 April 2020

Published on: 11 June 2020

Topic editor: Nesrine Akkari

Section editor: Max Barclay

Desk editor: Danny Eibye-Jacobsen

Printed versions of all papers are also deposited in the libraries of the institutes that are members of the EJT consortium: Muséum national d'histoire naturelle, Paris, France; Meise Botanic Garden, Belgium; Royal Museum for Central Africa, Tervuren, Belgium; Royal Belgian Institute of Natural Sciences, Brussels, Belgium; Natural History Museum of Denmark, Copenhagen, Denmark; Naturalis Biodiversity Center, Leiden, the Netherlands; Museo Nacional de Ciencias Naturales-CSIC, Madrid, Spain; Real Jardín Botánico de Madrid CSIC, Spain; Zoological Research Museum Alexander Koenig, Bonn, Germany; National Museum, Prague, Czech Republic. 